\title{
مدى تطبيق إدارة الجودة الشاملة في كليات وأقسام إدارة السياحة والفنادق في الجامعات الأردنية
}

\section{من وجهة نظر الطلاب}

The Applicability of Total Quality Management at the Faculties and Departments of Hotels and Tourism Management at the Jordanian Universities as Perceived by the Students

\author{
Dr. Hadi Nasir Al-Ajlouni \\ Assistant Professor/Al-Ahliyya Amman University \\ (previously)/Jordan \\ Ajloouni@Yahoo.Com
}

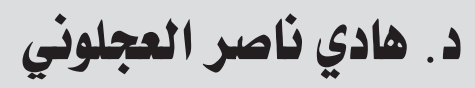

أستاذ مساعد / جامعة عمان الأهلية (سابقاً)/الأردن المهاعي

Received: 28/ 11/ 2018, Accepted: 23/ 2/ 2019 DOI:

http: //journals.qou.edu/index.php/eqtsadia
تاريخ الاستلام: 28/ 28 / 2018 2018م، تاريخ القبول: 23/ 23/ 2019م.

E - ISSN: 2410 - 3349

P - ISSN: 2313 - 7592 


\section{مقدمة:}

تعتبر المؤسسات التعليمية الجامعية، بمثابة بناء تنظيمي

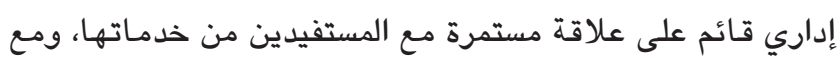

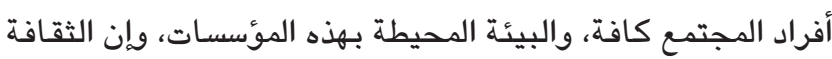

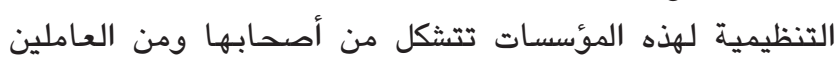

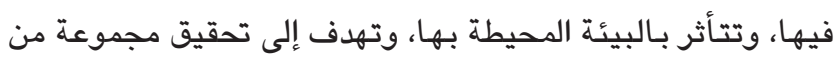

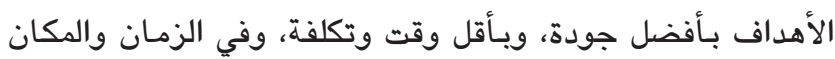

المناسبين.

وقد أكدت السياسات في المؤسسات التعليمية الجـامعية في الدول المتقدمة على أن التخطيط لإدارة الجودة الشاملة وضمان التهان

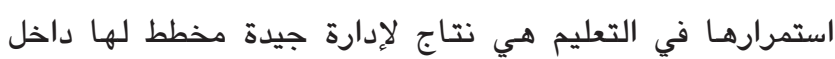

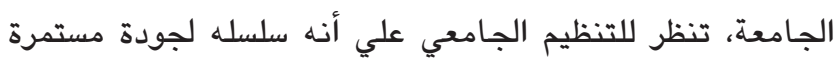

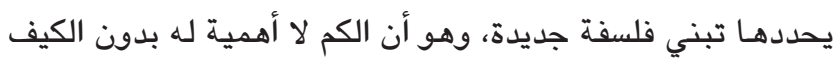

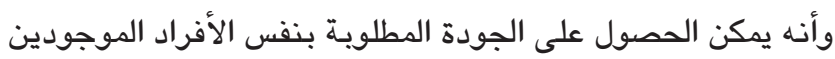

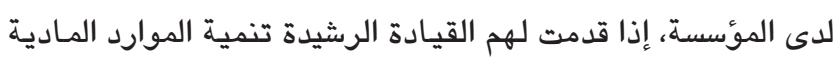

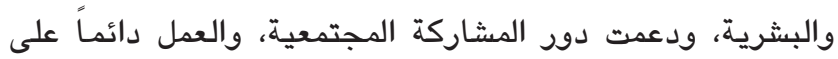
توكيد الجودة والمساءلة، والتدريب المناسب، وتوفير مناخ تربوي لودي

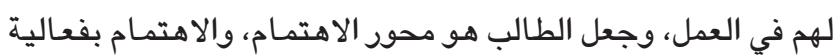
قاعة الدراسة وتقسيم الطلبة إلى مجموعات من أجل التحسين

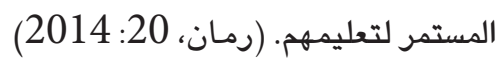
يعتبر تبني متطلبات إدارة الجودة الشاملة في المؤسسات

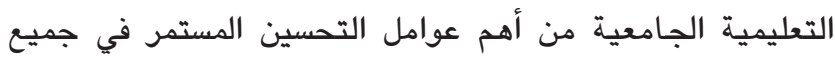

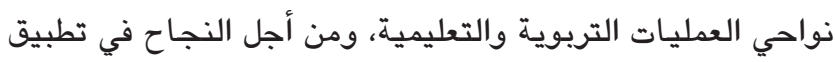

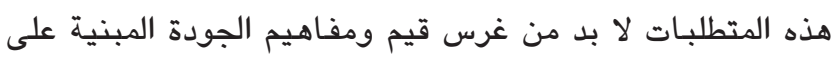

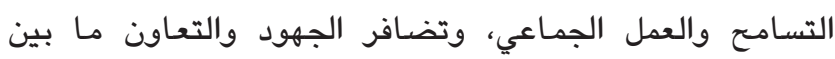

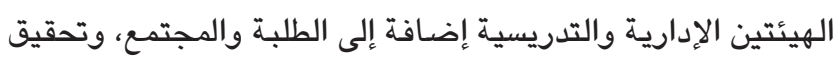

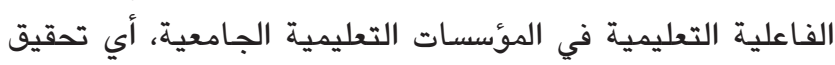

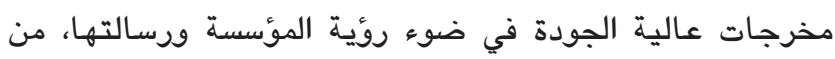

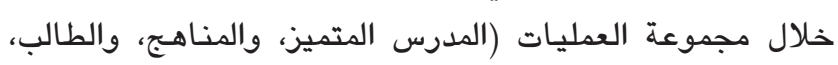
والبيئة التعليمية)، وذلك بمراجعة المنتج التعليمي، وتطوير التعليم

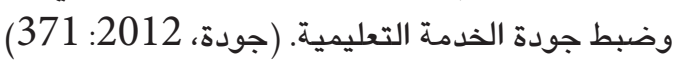

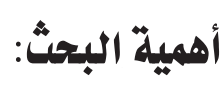

تتناول هذه الدراسة موضوع إدارة الجودة الشاملة وتطبيقها

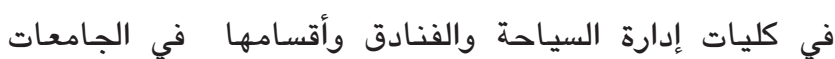

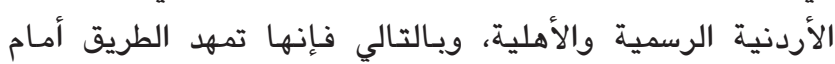
الباحثين للتعمق في دراسة موضوع إدارة الجودة الشاملة وتطبيقها ولاهيها

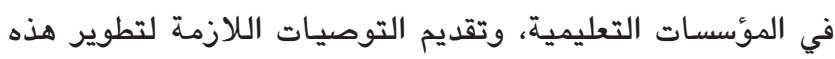
المؤسسات ويخاصة المؤسسات العاملة في مجال التعليم السياحي

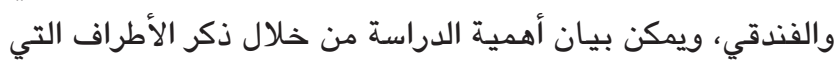

هدفت هذه الدراسة إلى التعرف على درجة تطبيق إدارة الجودة الشاملة،وذلك في الجامعات الأردنية الرسمية والأهلية والتي لديها كليات وأقسام سياحة وفنادق، وعددهـا اثنتا عشرة،

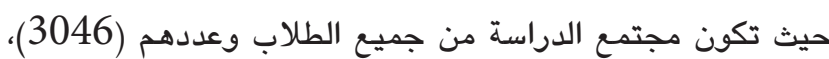
ويلخ حجم العينة (491) طالباً، وتم استخدام استبانة صمدت التع خصيصـاً لجمع المعلومات المطلوية، حيث تم تحليل الاستبانات بـاستخدام الإحصاء الوصفي وتحليل التباين. توصلت الدراسة إلى أن درجة تطبيق إدارة الجودة الشاملة كانت مرتفعة على كل الألى

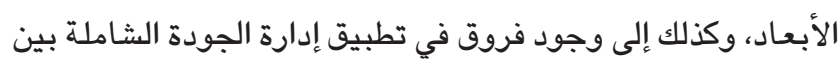

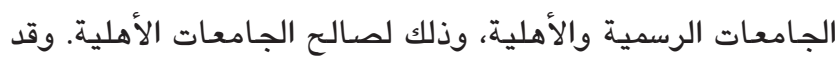
اختتمت الدارسة بمجموعة من التوصيات أهمها أن تقوم إدارات الجامعات بـالمواءمة بين العمليات التربوية والتعليمية ومتطلبـات سوق العمل السياحية والفندقية.

كلمات مفتاحيّة: إدارة الجودة الشاملة، كليات وأقسام السياحة والفنادق في الجامعات الأردنية.

\section{Abstract:}

This study sought to explore the applicability of Total Quality Management at the faculties and departments of Hotels and Tourism Management in 12 Jordanian public and private Universities. The population of the study consisted of all the students, 3046. A sample of 491 students was selected. Data was collected using questionnaires and it was analyzed using the Descriptive Analysis and Analysis of Variance. The study revealed that the level of applying Total Quality Management was high in all dimensions. In addition there were significant differences between the public and private universities in applying Total Quality Management, in favor of private universities. One of the most important recommendations is that universities should focus on matching the pedagogical and educational processes with the demands of the sector of Hotels and Tourism market.

Keywords: Total Quality Management, Faculties and Departments of Hotels and Tourism at Jordanian Universities. 


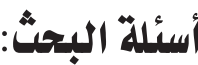

هدفت هذه الدراسة للإجابـة على الأسئلة التالية: ما مدى تطبيق إدارة الجودة الشاملة في الجامعات

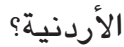

هل هناك فروق في تطبيق إدارة الجودة الشاملة بين الجـامعات الأردنية الرسمية والأهلية؟ فئي فئي

هل هيناك فروق بين استجـابـات أفراد عينة الدراسة حول

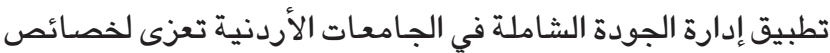

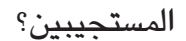

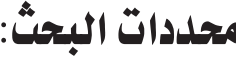

يمكن الأخذ بنتائج البحث والعمل على تعميمها في ضوء

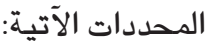

- - اقتصر هذا البحث على الجـامعات الأردنية الرسمية والأهلية والتي لديها برامج سياحية وفندقية للعام الدراسي 2014-2013)

- كما واقتصر على طلبة الجامعات في كليات إدارة

السياحة والفنادق وأقسامهمـا.

- ـ واقتصر أيضًاً على استخدام الأداة التي تضم المجالات الثمانية الآتية: الوعي بمفهوم إدارة الجودة الشاملة، والاستراتيجية العامة، والعملية التريوية، والعملية التعليمية، والتقنيات، وخدمات الطلاب، والعلاقـات التنظيمية، والتغذية الراجعة.

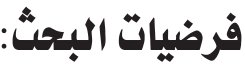

سيتم اختبار الفرضيات العدمية (H0) التالية في كليات إدارة السياحة والفنادق وأقسامهما في الجامعات الأردنية الرسمية الرية

$$
\text { والأهلية والتي تنص على ما يلي: }
$$

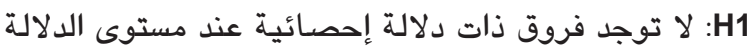

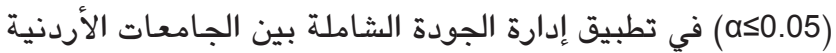
الرسمية والأهلية من وجهة نظر إلطارة الطودة الطابة

H2 لا توجد فروق ذات دلالة إحصائية عند مستوى الدلالة

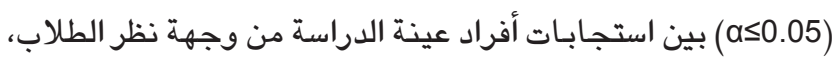

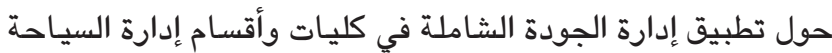

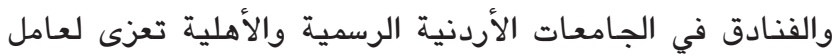

H3 لا توجد فروق ذات دلالة إحصائية عند مستوى الدلالة

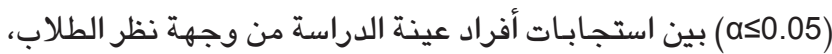

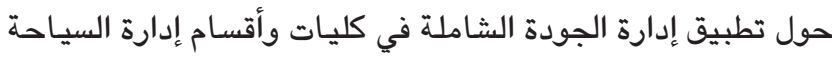

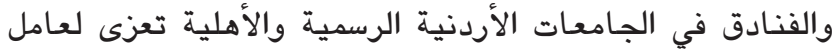

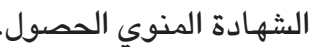

H4 لا توجد فروق ذات دلالة إحصائية عند مستوى الدلالة

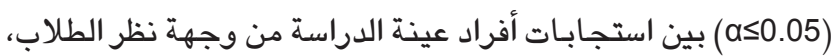

قد تستفيد من هذه الدراسة وهي: وزارة التعليم العالي والبحث

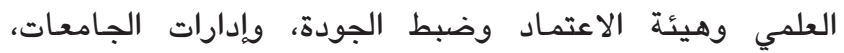
والهيئات التدريسية، والطلاب، ومن ثم الانتقال إلى بيان كيفية استفادة هذه الأطراف من هذه الدراسة، ونشير إلى أول جهة منها

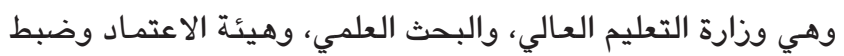

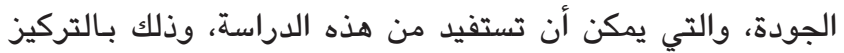

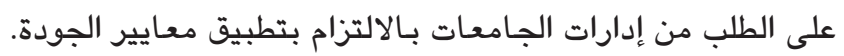

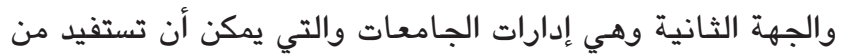
هذه الدراسة بالتعرف على مدى تطبيق إدارة الجودة الشاملة لديها مها يساعدها على معرفة ددى تطبيق إدارة الجودة الشاملة لدئ إديها

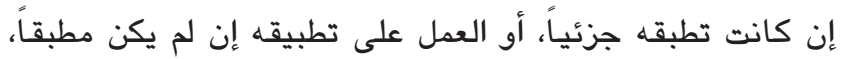
والمحافظة عليه واستمرارية تطبيقه في حالة تطبيقه بشكل كامل.

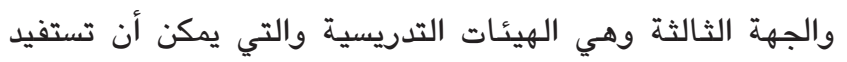

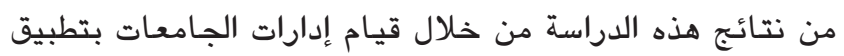

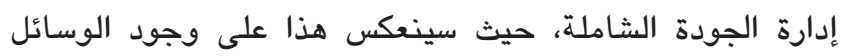

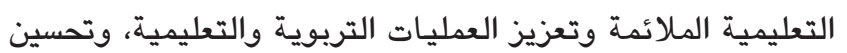

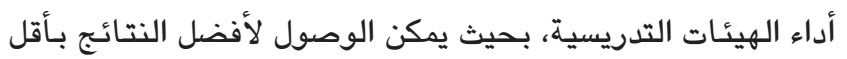

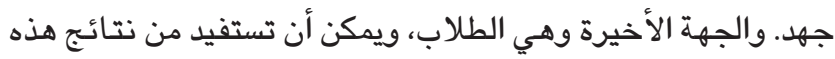

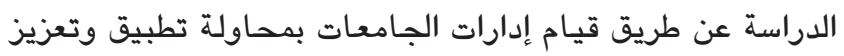

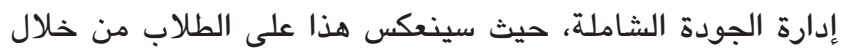

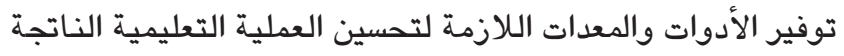

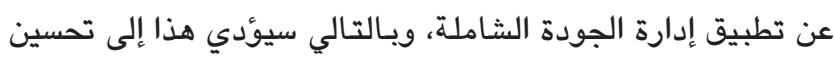

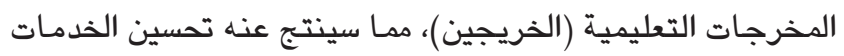
المقدمة في القطاع السياحي والفندقي وتطويره بشكل عام.

\section{مشكالة البحث:}

هناك حاجة كبيرة إلى تحسين سمعة الأردن ومكانته

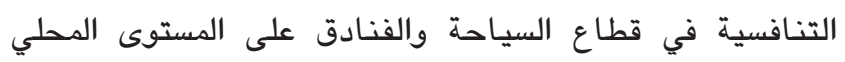
والإقليمي والدولي، وهذا يفرض العمل على توفير عدد من التئ

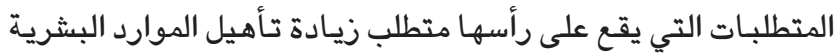

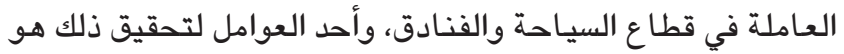

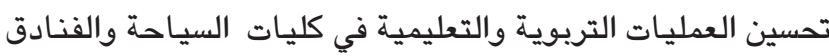

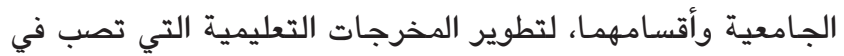

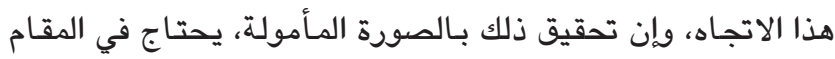

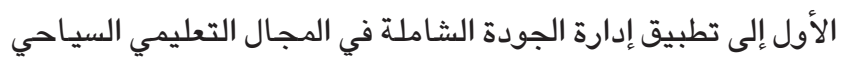
والفندقي الجامعيين، فهل عملت المؤسسات التعليمية الأردنية المتخصصة في هذا الهجال على تطبيق إدارة الجودة الشاهلة؟

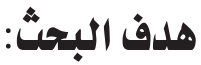

يتمثل الهدف العام لهذه الدراسة في الكثف عن مدى تطبيق إدارة الجودة الشاملة في كليات وأقسام إدارة السياحة والفنادق في لإدان الجامعات الأردنية الرسمية والأهلية من وجهة نظر الطلاب. 
وتقديس الإمبراطور، والذي كان يعتبر الوسيط بين الإله والناس.

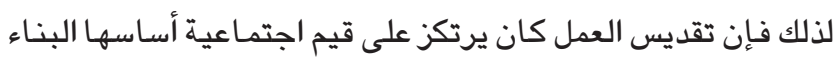

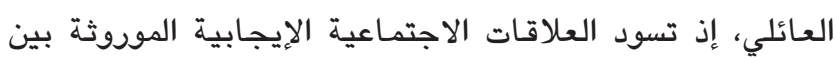

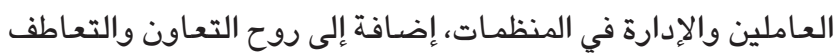
والمشاركة، لذلك نادراً ما تحصل الصراعات الصات الفرات الفردية في المنظمات،

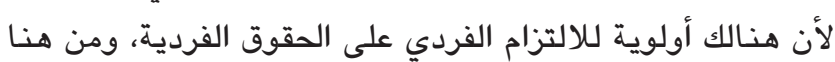

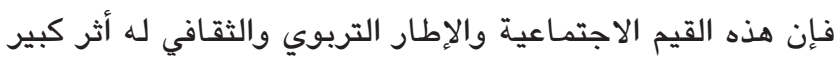

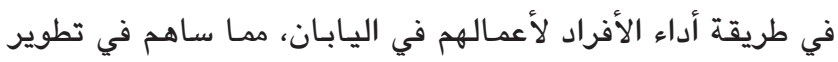

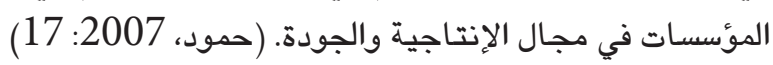
يعتبر الإطار التربوي التعليمي في اليابان هو الوسيلة التي

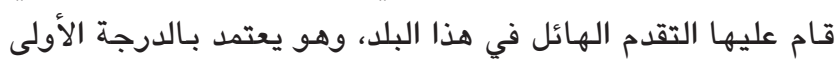

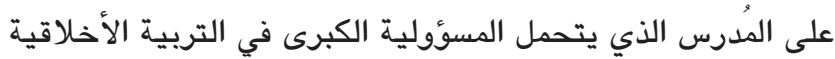

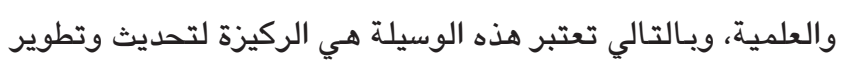

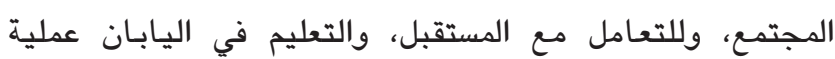

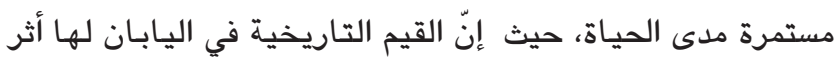

قوي على التعليم. (الزواوي، 2008: 74: 7.

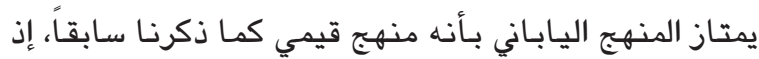

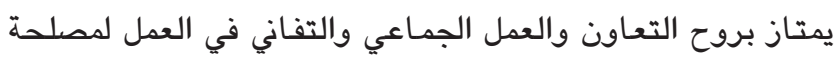

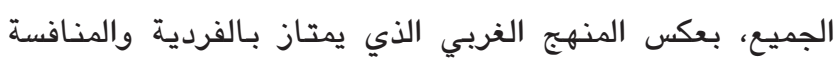

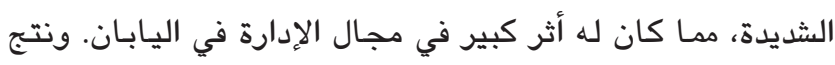

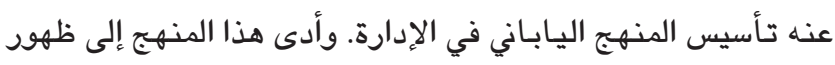

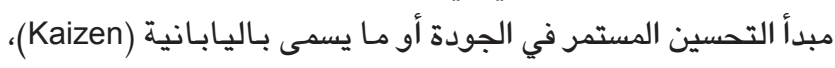
ونتج عنه فِرق تحسين الجودة (Quality Improvement Teams)،

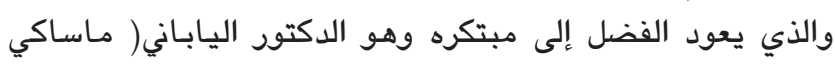

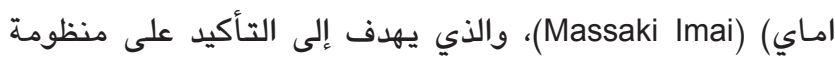

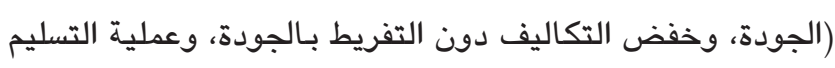

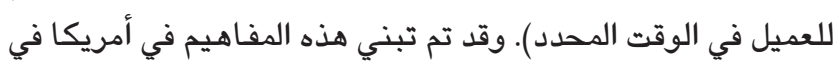
بداية السبعينيات. (Goetsch and Davis, 2010:494)

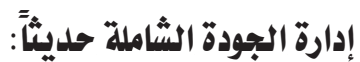

حظي هذا الدفهوم بتعريفات كثيرة، ويعود سبب التباين

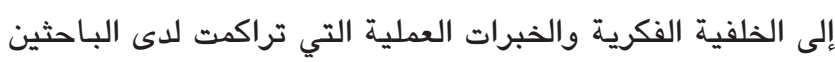

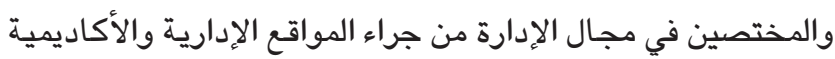
والاستشارية التي شغلوهـا لسنين طويلة، والتي شكلت منطلقاتهم الإدارية والاكادية

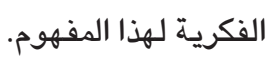

عرف (Jablonski, 1991: إدارة الجودة الشاملة أنها "شكل

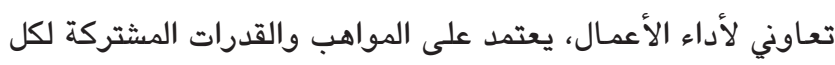

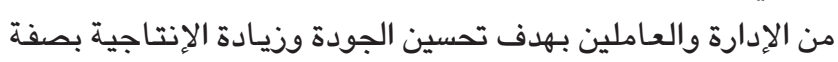
مستمرة من خلال فرق العمل “.

وعرفها (Dale \& Cooper, 1992: 19) "عملية يشارك بها فرقال كل شخص في المنظمة، من أجل تزويد المنتج والخدمة والتي تحقق لعقات

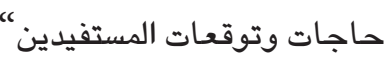

حول تطبيق إدارة الجودة الشاملة في كليات وأقسام إدارة السياحة

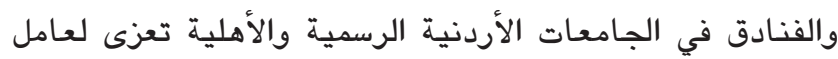

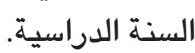

\section{نشأة وتطور الجودة:}

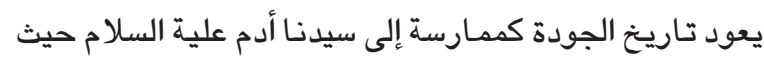

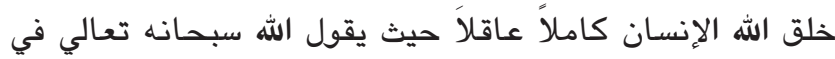

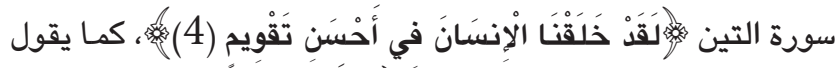

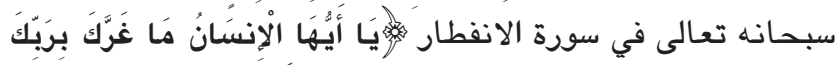

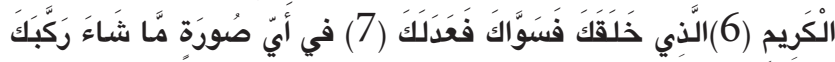

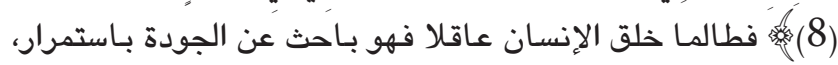

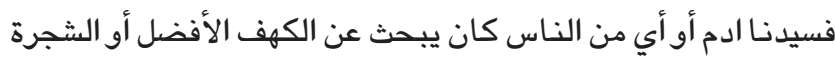

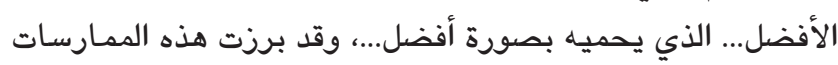

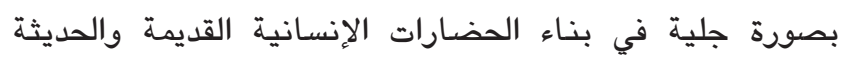
(عساف ومسودة، 2008: 12). فالحضارة البابلية في القرن الثامن

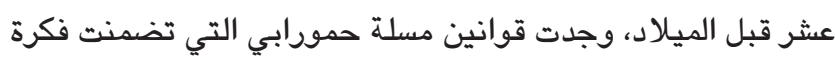

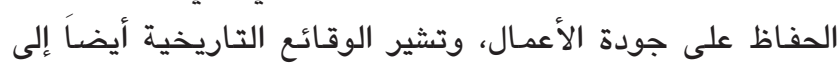

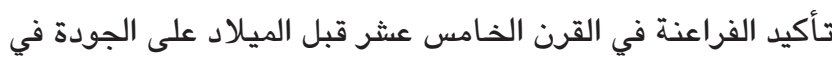

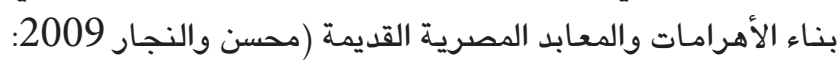
478). وحافظ الأنباط على الجودة بين القرن الثاني قبل الميلاد

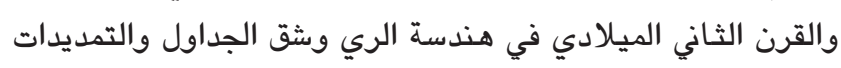

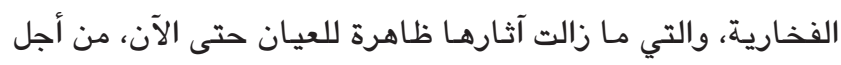

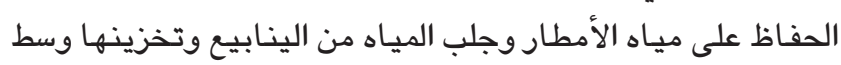

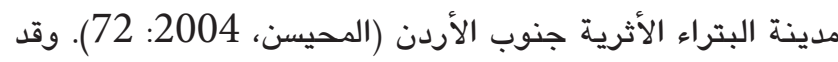

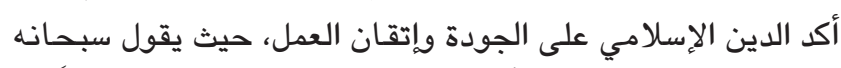

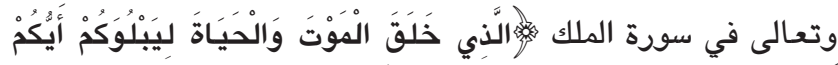

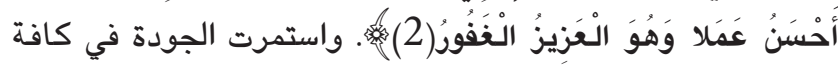

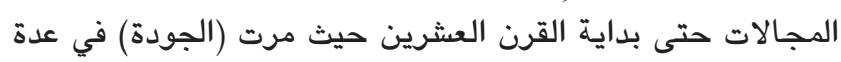

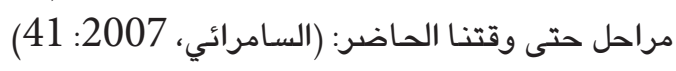

\section{تطور الجودة في المنظمات اليابانية:}

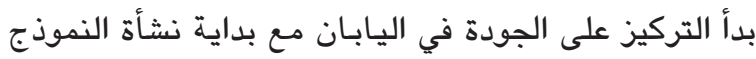

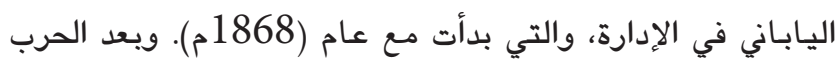
العالية الثانية بدأ إدورد ديمنج (Edwards Deming) وهو الحاني أحد

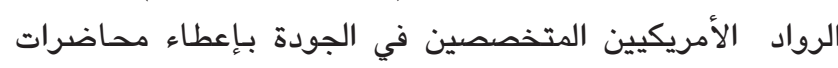

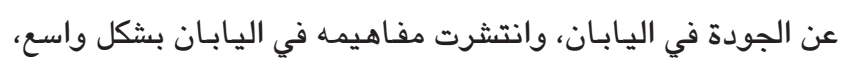

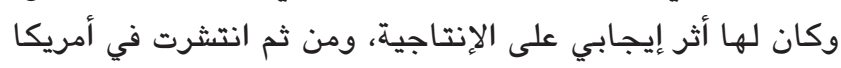

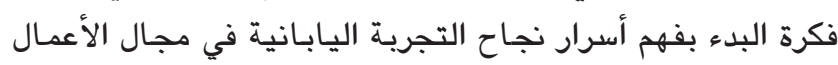

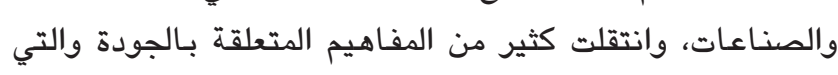

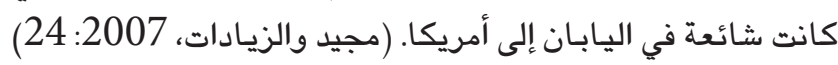

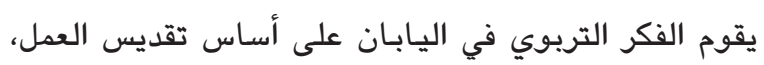

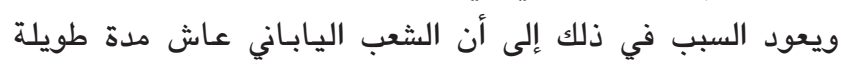
من الزمن في إطار تربوي وثقافي يستمد قيمه من عبادة الأرواح 
ظاهرة إدارية تعمل على توحيد كل النشاطات والنظم والعمليات

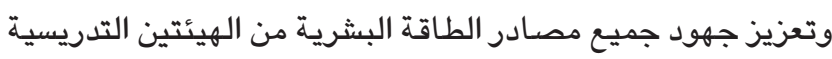

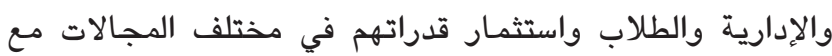

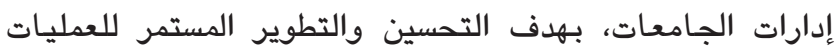
التربوية والتعليمية، وجودة المخرجات لإرضاء كافة المستفيدين.

\section{الدراسات السابقة:}

شهد العالم كثيراً من التغييرات الملحوظة، في المجالات

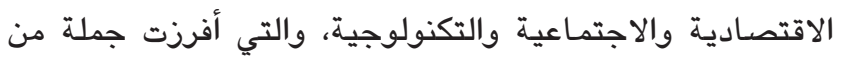

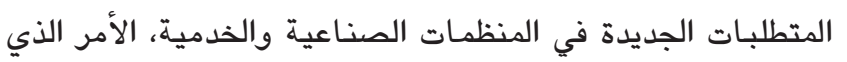
فرض على هذه المنظمات ضدرورة تغيير أساليبها التقليدية في الإدارة وتبني المفاهيم الإدارية الحديثة، وعلى رأسها تبني الني إدارة

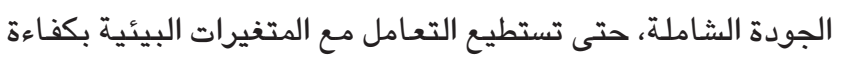
وفعالية، ولم يكن العالم العربي بعيداً عن هذه المتغيرات، واستجابـة المعابة

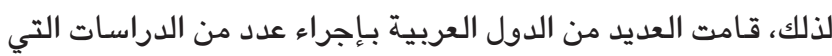
تناولت موضوع إدارة الجودة الشاملة بما فيها الأردن. أجرى (العياشي وكريمة، 2019) دراسة في الجزائر هدفت إلى

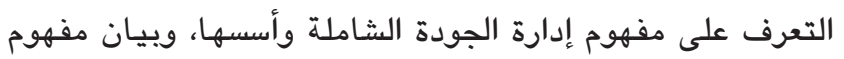

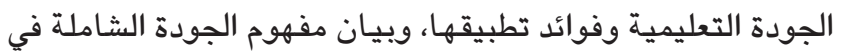
التعليم من منظور إسلامي. ومن أجل ذلك قـام الباحثان بـاستنبـاط وفئان معايير جودة التعليم في ضوء المبادئ التي دعا إليها الإسلام

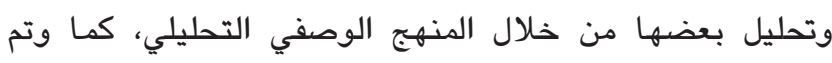

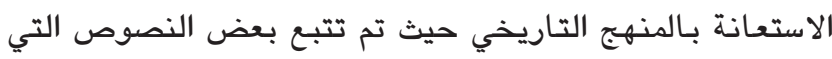

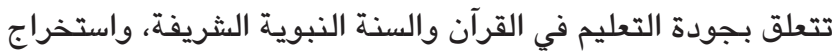
الأدلة والشواهد من كتاب الهه وسنة رسوله الكريم على مبادئ

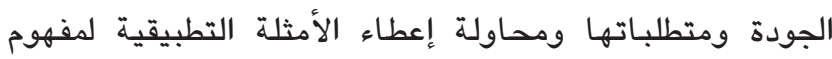

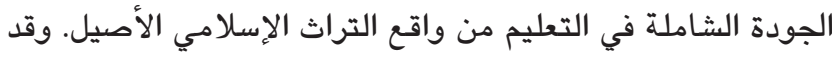

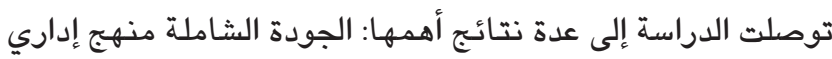

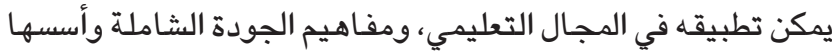
والتي ينادي بها الفكر الغريي منبعه وأساسه وارد في الإسلام،

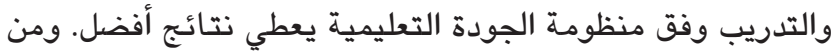

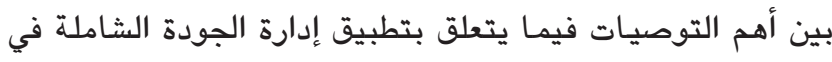

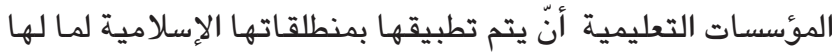

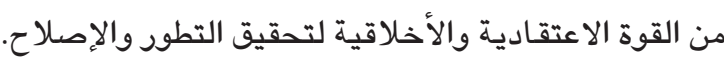
كما أجرت سليمان (2019) دراسة في السودان، هدفت إلى

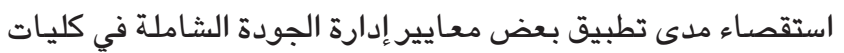

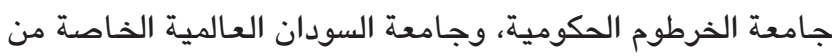

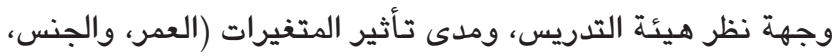

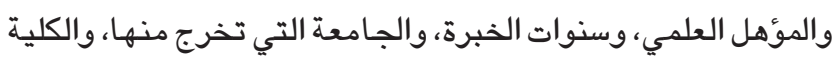

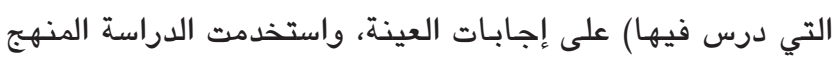
الوصفي الإحصائي. ولقد طورت الباحثة استبانة من (42) فقرة؛

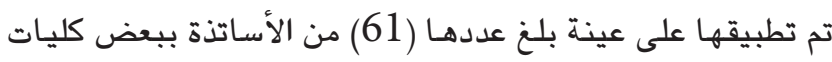

ويشير (McDermott et al, 1993: 234) بأنها "ثقافة التحسين المستمر في جميع الجوانب من قبل كل شخص وفي جميع

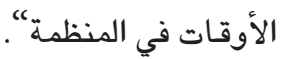

أمـا (Ross, 1999: فقل عرف إدارة الجودة الشاملة بـأنها

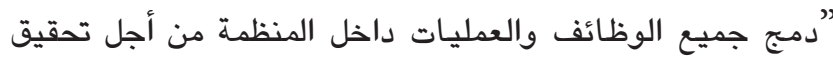
التحسين المستمر للجودة في المنتجات والخدمات، والهدف هو إرضاء المستفيد “

وعرفها (Goetsch and Davis, 2010: لمحاولة إتمام الأعمال من خلال تعظيم تنافسية المنظمة من خلال التطوير المستمر لجودة منتجاتها وخدماتها وأفرادهـا وعملياتها وبيئاتها.

أتفق كل من (Jablonski 1991) و) Dale \& Cooper (1992)

على أن إدارة الجودة الشاملة تعتمد على العمل الجماعي، وتعاون

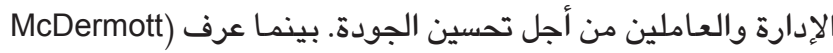

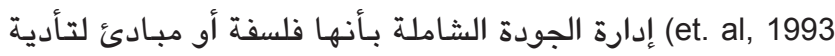

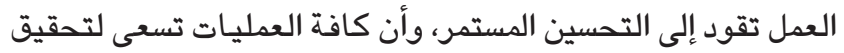

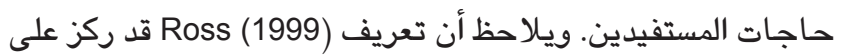
أن إدارة الجودة الشاملة تركز على مفهوم إدارة النظم الذي يريط بين بين العمليات والمخرجات، وذلك لتحقيق رغبات المستفيدين. فيما ركز تعريف Goetsch and Davis, (2010) على أن إدارة الجودة الشاملة

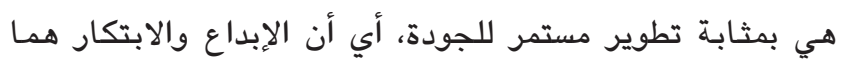

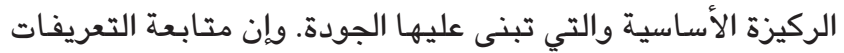
السابقة تكشف عن مجموعة من العناصر أو المقومات الأساسية التي يمكن تعريف إدارة الجودة الشاملة على أساسها، ومن أهمها:

أولاً: أن إدارة الجودة الشاملة فلسفة تعني بعدد مهم من

القيم الأساسية التي من أبرزهـا: - - مالعمل الجماعي ودور الفريق. - ميمة التركيز على جودة الأداء.

- ـ قيمة التركيز على العملاء، والعمل على تحقيق أهدافهم ومصالحهم بـالترابط مع أهداف المنظمة ومصالحها.

- - ق قيمة التركيز على العاملين والمجتمع، والعمل على تحقيق

أهدافهم ومصلحتهم بـالترابط مع أهداف المنظمة ومصـالحها. ـ ـ قيمة التطوير والتحسين المستمر، بما يضمن تحقيق البقاء

والارتقاء للمنظمة.

ويذلك فإنه يمكن القول بـأن إدارة الجودة الشاملة، فلسفة كلية تركز على النظام الكلي للمنظمة، بهدف تطويره بـاستمرار ليكون قادراً على بناء روح العمل الجماعي، وعلى بناء الترابط اللازم

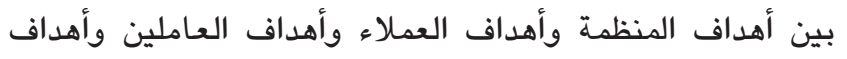
المجتمع، بما يؤدي إلى تحقيق جودة العمليات والمخرجات. ويناءً علية فيمكن تعريف إدارة الجودة الشاملة في التعليم الجامعي بـأنها: 


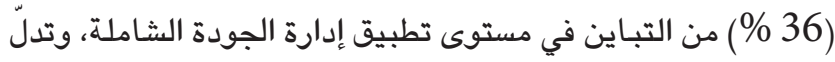

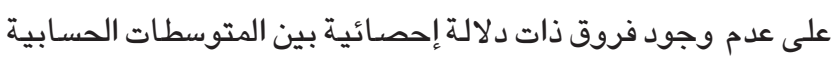

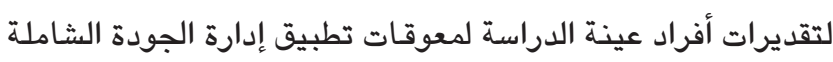
تعزى لمتغيرات الجنس والعمر وسنوات الخبرة والمركز الوظيفي.

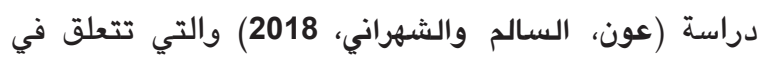
تطوير إدارة الجودة الشاملة في نظام التعليم العالي في المملكة

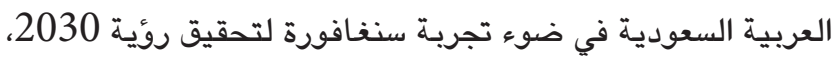

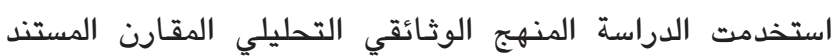

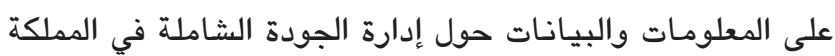

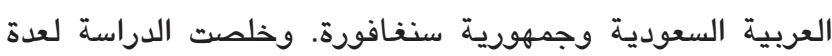

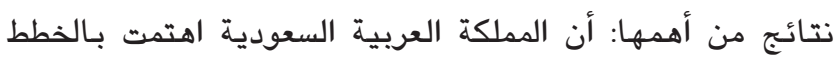

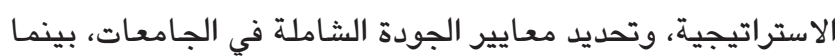

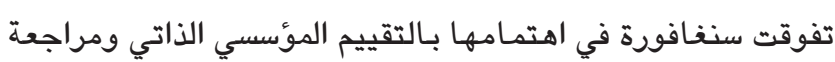
الخطط الاستراتيجية ومدى ارتباطها بالخطة الاستراتيجية للدولة.

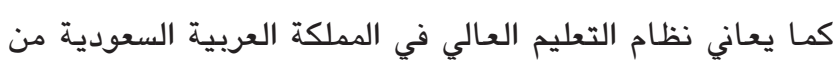

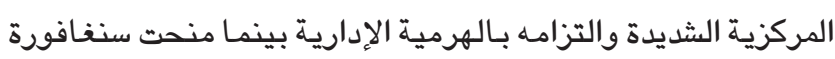

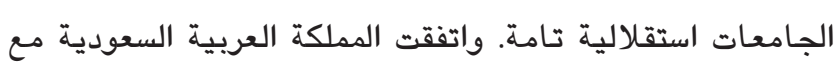

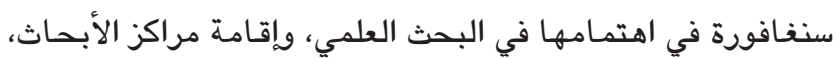

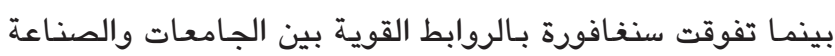

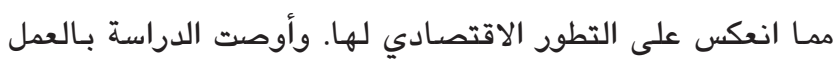

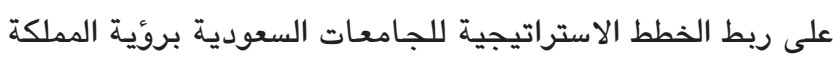
2030. ومنح الجامعات الاستقلالية، وربط برامجها التعليمية

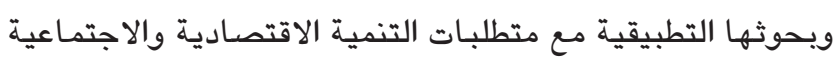

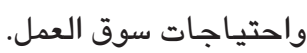

وهدفت دراسة محمد (2018) إلى التعرف على مدى تطبيق مبادئ إدارة الجودة الشاملة في كليتي الاقتصـاد والعلوم الإدارية العادية

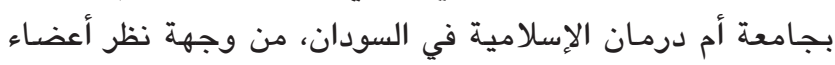

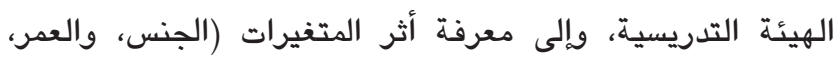

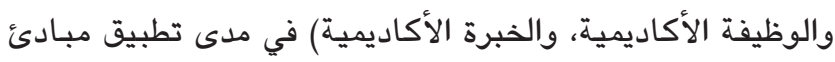

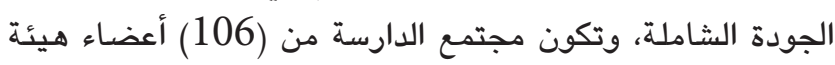

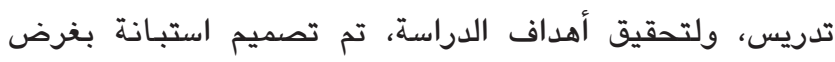

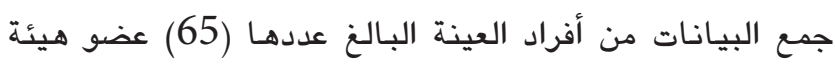

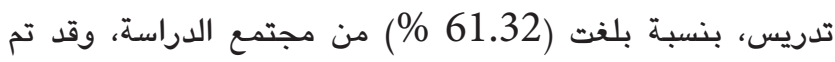

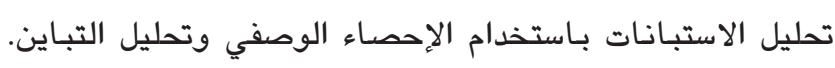

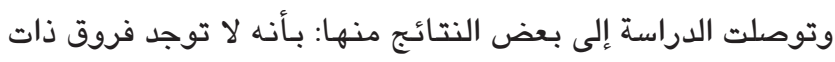

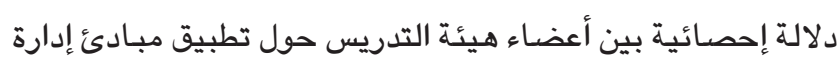

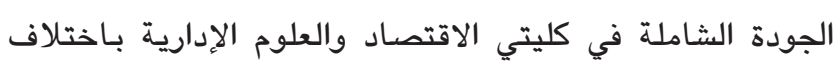

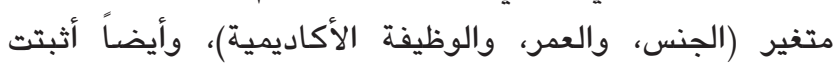

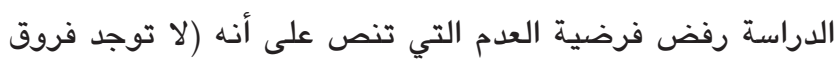
ذات دلالة إحصائية في درجة تطبيق مبادئ الجائ الجودة الشاملة في الإني

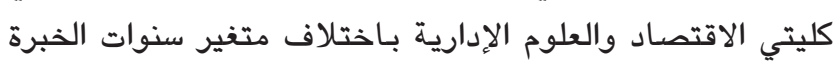
ال،أكاديمية) وقبول الفرضية البديلةوالتي تنص الإدلية على أنه (يوجد

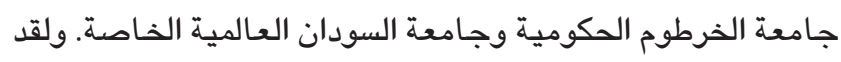

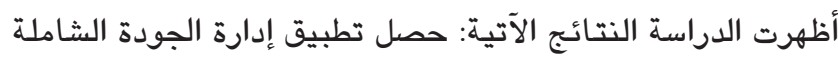

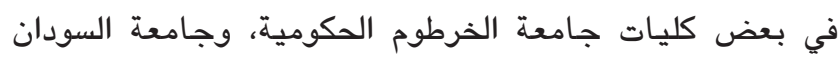

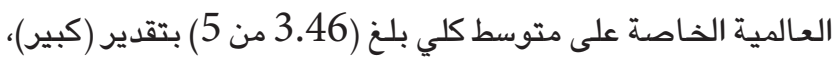
ويخصوص المجالات حصل مجال تهيئة متطلبات الجودة في

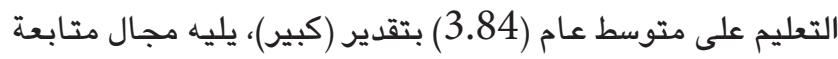

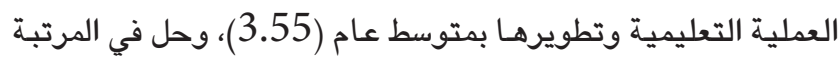

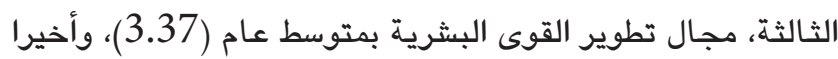

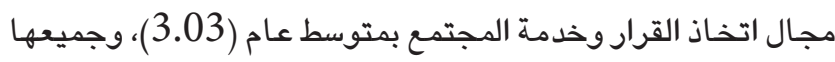

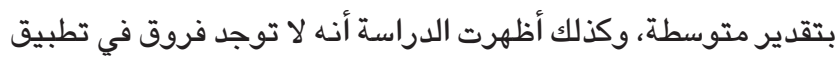
بعض معايير إدارة الجودة الشاملة في مؤسسات التعليم العالي

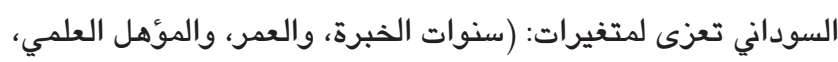

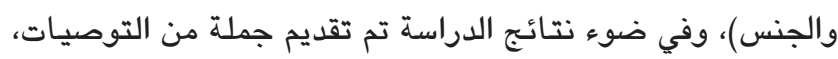
لزيادة الوعي، وتفعيل تطبيق بعض التور معايير إدارة الجودة الشاملة

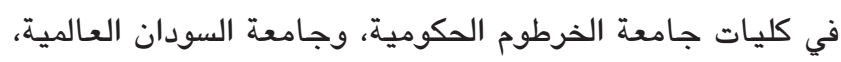

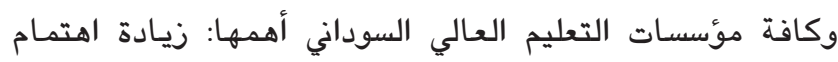

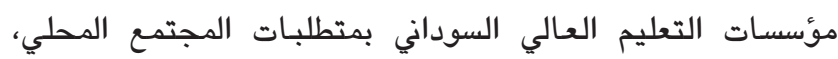

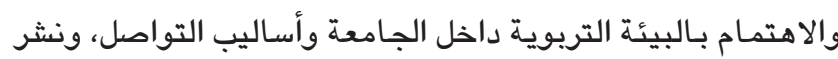

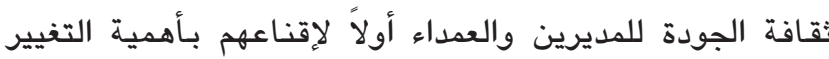
وتحسين الأداء وأهمية معايير الجودة في مؤسسات التعليم العالي لإنداء

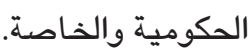

وكما أجرى (الذيابات والذيابات، 2018) دراسة هدفت إلى توضيح أثر معوقات تطبيق إدارة الجودة الشاملة في الجامعات الذات

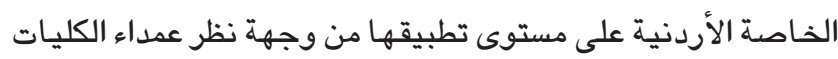

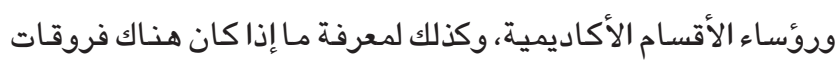

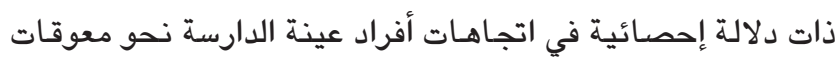

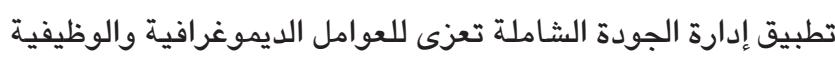

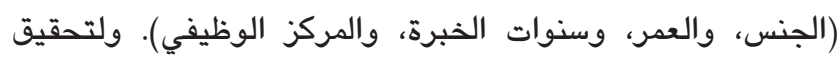

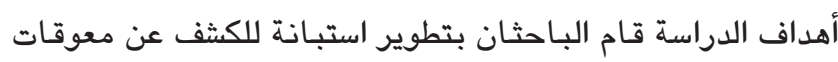

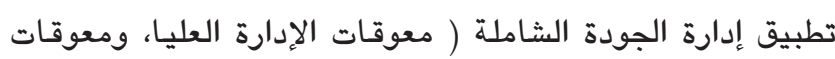

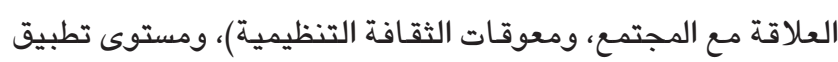

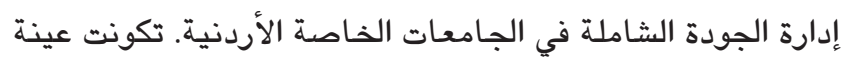

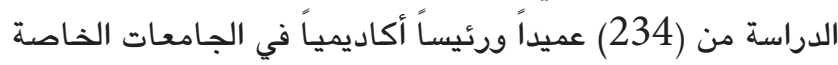

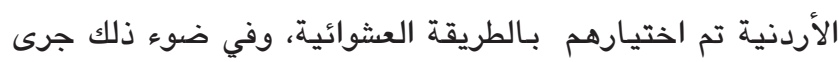

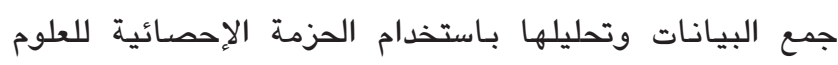

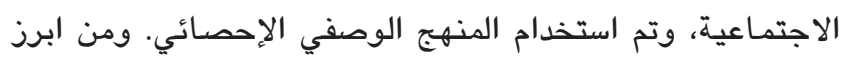

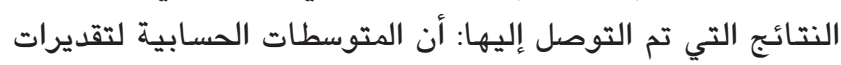

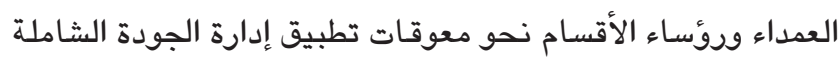

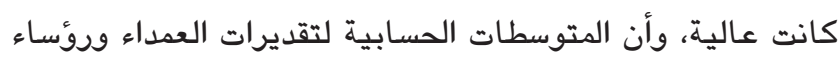

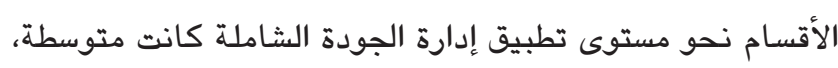

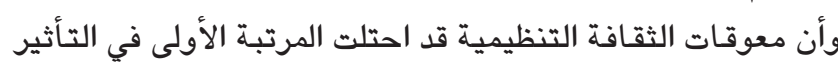

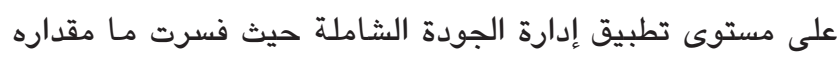




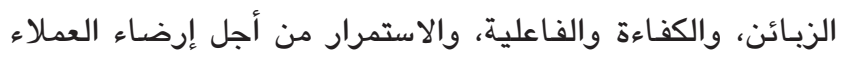

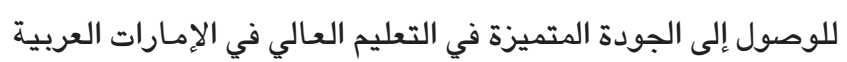

المتحدة.

Mikauskas, Jasinskas and Svagzdiene,) كما أجرى

2012) دراسة (فيلتوانيا) هدفت إلى تشخيص وضع المعايير التي

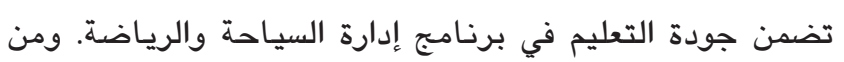
أجل تحقيق أهداف الدارسة قام الباحث بمراجعة الدفاهيم المتعلقة

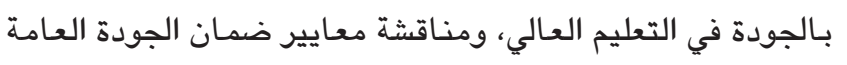

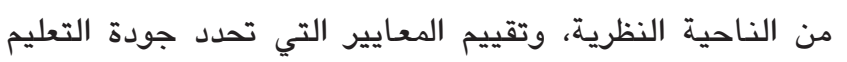

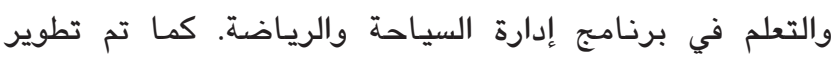
استبانة اشتملت على (105) فقرات، تقيس عوامل تحديد جودة التهات

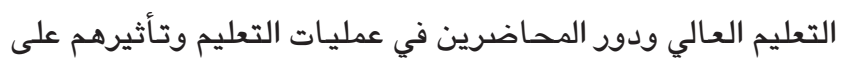

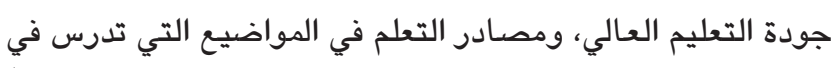

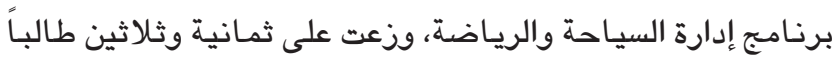

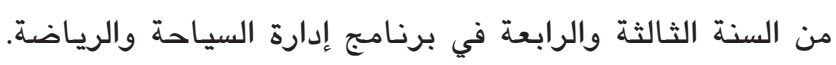

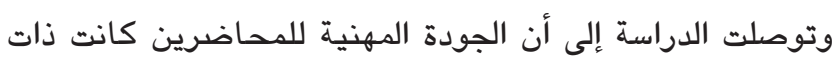

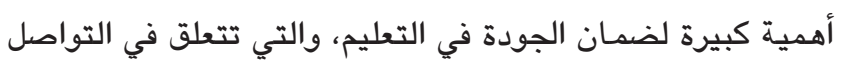

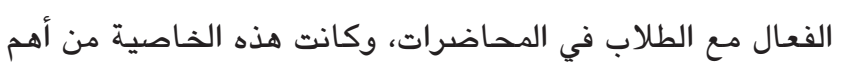

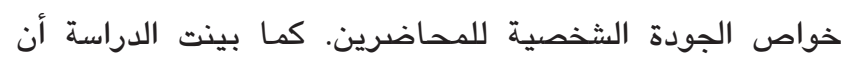

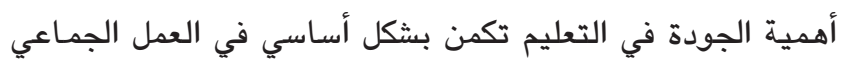

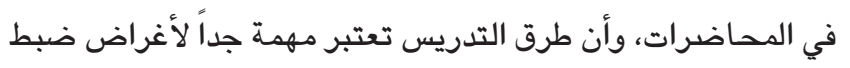

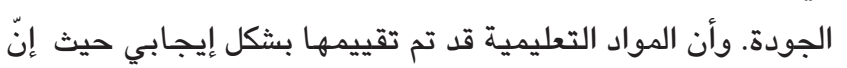
جميع مفردات هذا الجانب حصلت على تقييم أعلى من المتوسط.

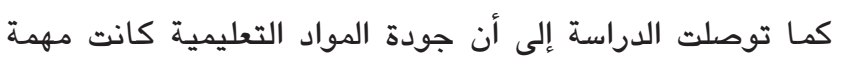

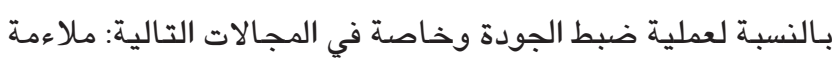

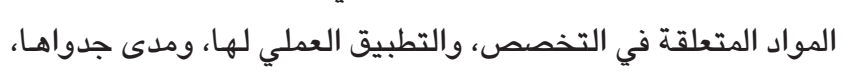
وإمكانية الوصول إلى المعلومات، وكفايتها. كما وأجرى (Salameh, Alzydat and Alnsour, 2011) دراسة في الأردن تهدف إلى قياس مدى تطبيق إدارة الجودة الشاملة

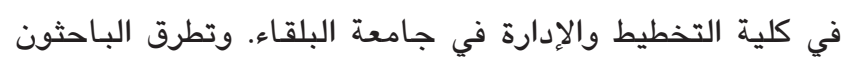

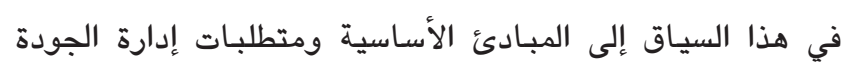

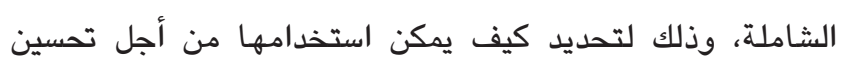

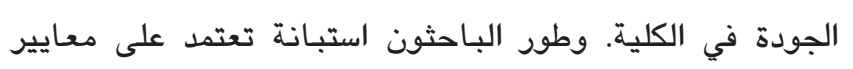

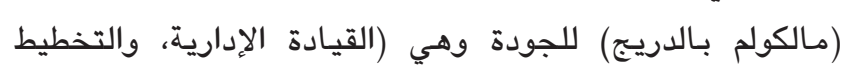

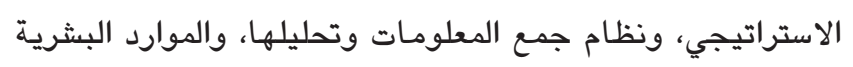

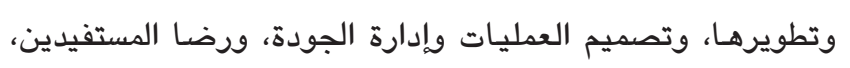

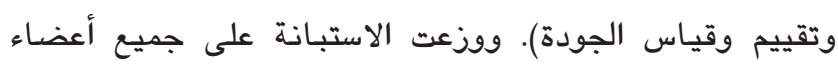
الإدارة والهيئة التدريسية والبالغ عددهم ثمانية وأروئيعون عضواً. توصلت الدراسة إلى أن هناك تركيزاً على عمل الفريق، والتحسين

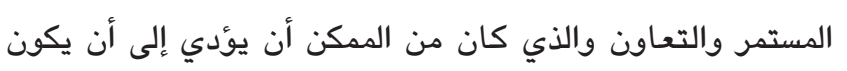

فروق ذات دلالة إحصائية في درجة تطبيق مبادئ الجودة الشاملة

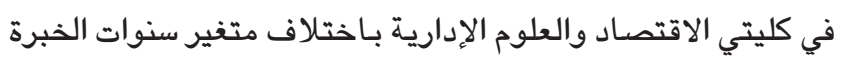

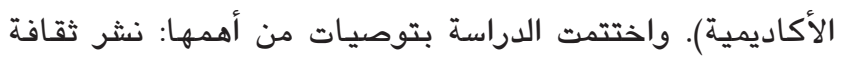
الجودة الشاملة بين أعضاء الهيئة التدريسية والإداريين والطلاب الهاب والعاملين.

كما وهدفت دراسة (Giorgidze, 2012) إلى تحديد العوائق والفجوات التي تحول دون تحسين إدارة الجودة في الجامعات الجدات

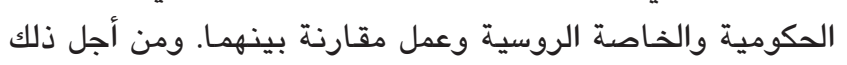

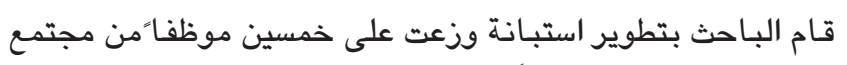
يتكون من (896) موظفاً من بينهم أعضاء من الهيئة التدريسية

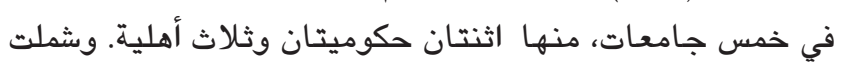

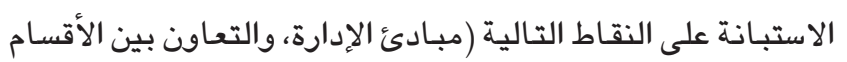

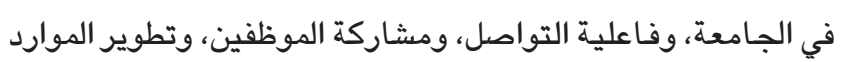

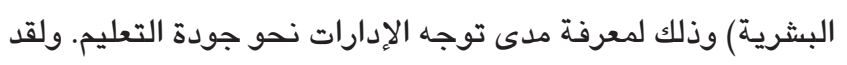

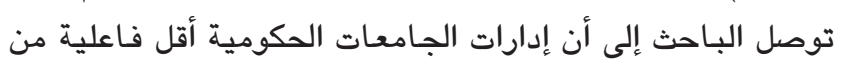

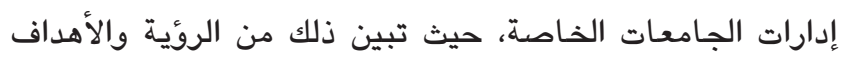

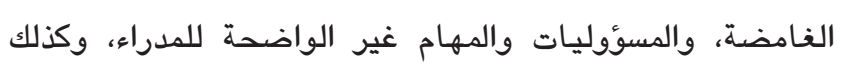

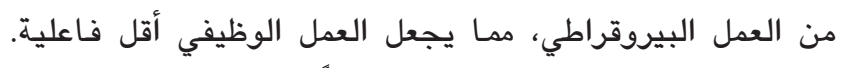

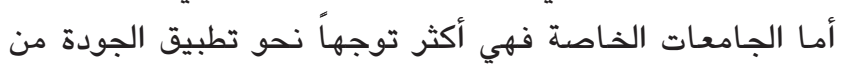

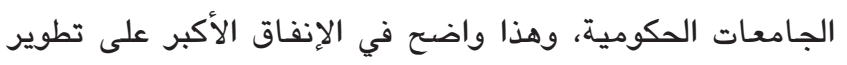

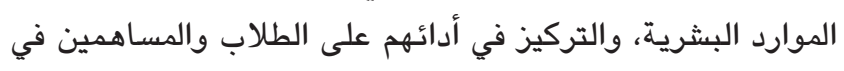

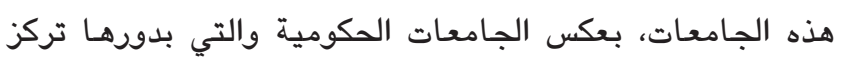

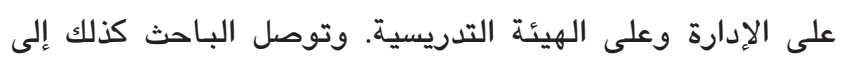

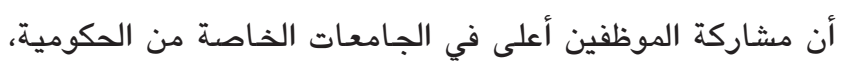

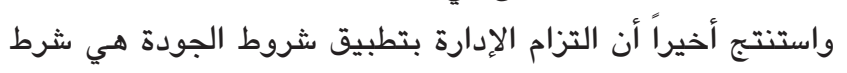
مسبق من أجل ضمان الجودة في الجامعات الترات وأجرى (Soomro and Ahmad, 2012) دراسة ركزت على إنى الجودة وتصميم نموذج لها في مجال التعليم العالي في الإمارات

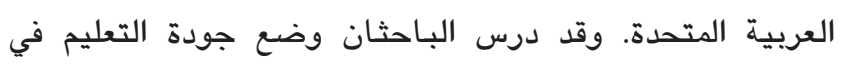

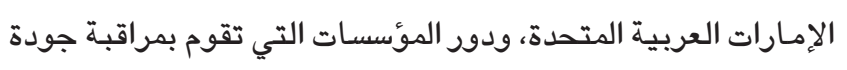

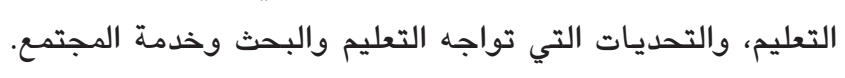

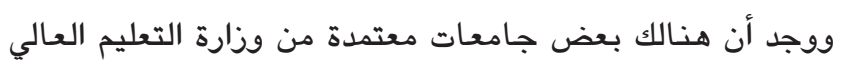
والبحث العالي، والبعض الآخر يتكون من جامعات أجنبية معتمدة

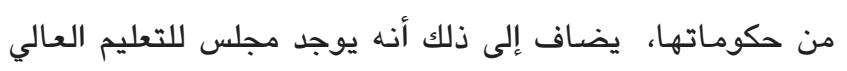

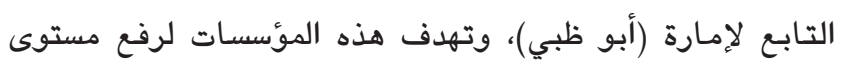

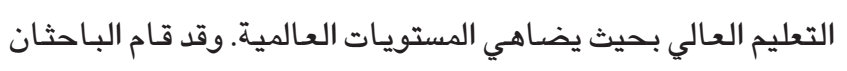
باستكشاف نموذج للحفاظ على الجودة الشاملة في مؤسسات

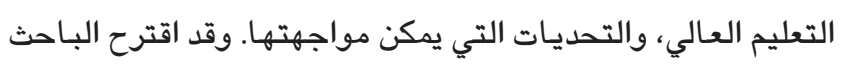

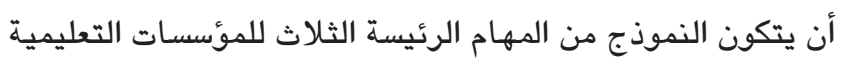

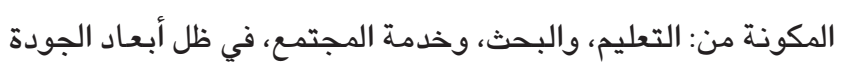

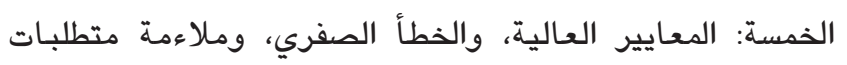


المعلوماتية والتكنولوجية إضافة إلى المنافسة في المستقبل،

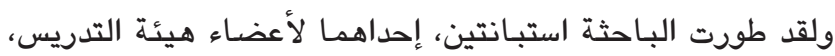

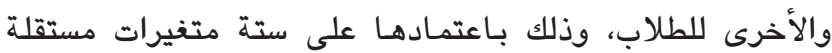
رئيسة لإدارة الجودة الشاملة وهي ( الوعي بإدارة الجودة الشاملة،

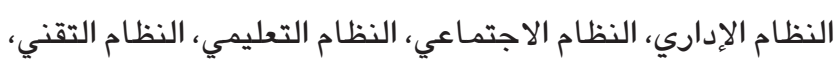
النظام الخدمي). وزعت الاستبانتين على عينة من (70) من أعضاء الإدياء

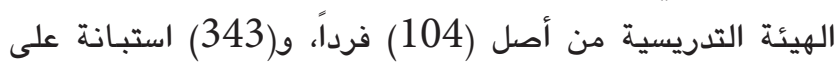

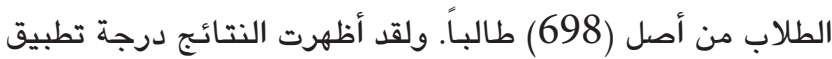
متوسطة لإدارة الجودة الشاملة في كليات التربية الرياضية في الجامعات الحكومية الأردنية، من وجهتي نظر كل من أعضاء الهيئة التدريسية والطلاب، وعلى جميع محاور إدارة الجودة الشاملة، حيث كان أكثر المحاور تطبيقا لإدارة الجودة الشاملة هو محور "النظام ولئل

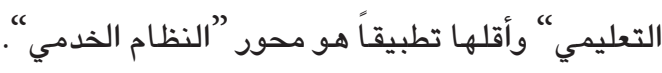
دراسة بدح (2003) والتي تتعلق بمدى أمكانية تطبيق مبادئ

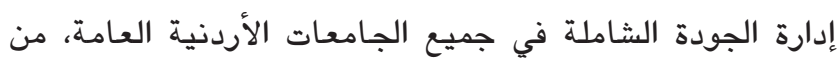
وجهة نظر عمداء ورؤساء الأقسام، ومديري الوحدات الإدارية. ولهذا الغرض طور الباحث أنموذج مقترح لإدارة الجودة الشاملة، والذي

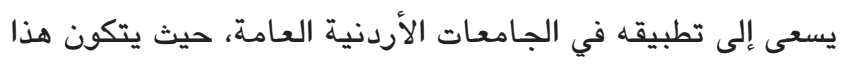
الأنموذج من مجموعة من الفقرات وهي كتالي: القيادة، ورسالة

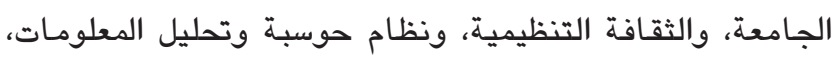

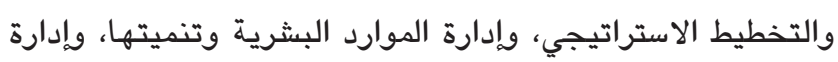

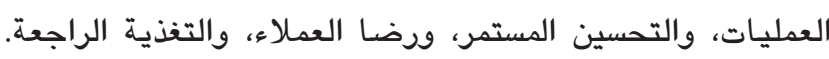
وتوصلت الدراسة إلى أمكانية تطبيق الأنموذج المقترح لإدارة

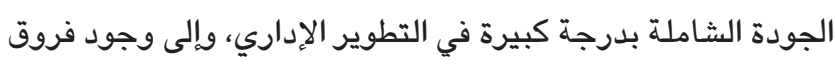
ذات دلالة إحصائية في درجة إمكانية تطبيق الأنموذج المقترح

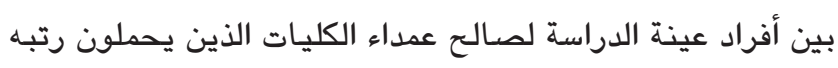

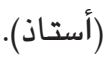

\section{ما يميز هذه اللدراسة عز اللدراسات السابقة:}

تناولت العديد من الدراسات السابقة موضوع تطبيق إدارة

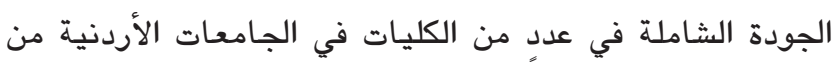

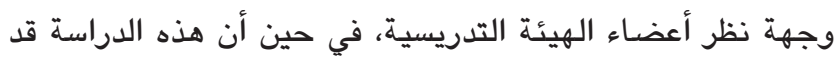
تناولت هذا الموضوع من حيث قياس مدى تطبيق إدارة الجودة الشاملة من خلال استطلاع رأي الطلبة، ضمن منال مدال التعليم السياحي والفندقي الجامعي، إضـافة إلى أن مجال التعليم السياحي والفندقي الجامعي يعتبر مجالاً حديثاً وواعداً، ومن شأن مثل هذه إنها الدراسة أن تساهم في الارتقاء بجودة الخدماهي بعات التعليمية السياحية

والفندقية ومخرجاتها.

منهجية الدراسة:

يهذف هذا الجزء إلى توضيح منهجية الدارسة؛ من حيث ذوع
الإداري مبدعاً وخلاقاً، ولم تتوفر قيادة إدارية مؤهلة، أو تدريب

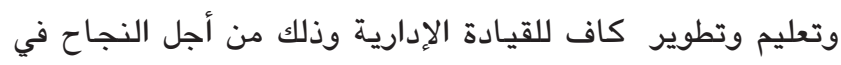
تطبيق إدارة الجودة الشاملة. وقد أوصى الباحثون بتبني مبادئ

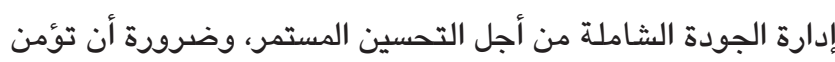
القيادة الإدارية بمفهوم إدارة الجودة الشاملة من أجل توفير البيئة

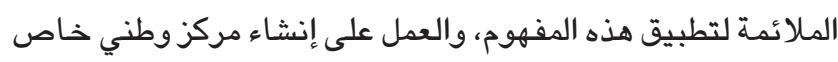

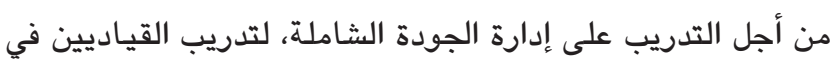
مجال التعليم، ومنح الشهادات في هذا الهجال.

Sabihaini, Liestyana, Yuli, Astuti and Widhy,) دراسة

2010) وقد أجريت هذه الدراسة في اندونيسيا وهدفت إلى تحليل مدى فاعلية تطبيق إدارة الجودة الشاملة في مجال التعليم العالي.

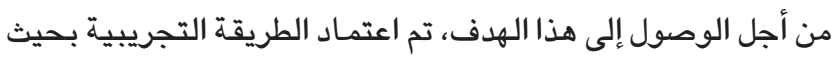
تم توزيع استبانة على الطلاب، تحتوى على المبادئ المتعلقة في

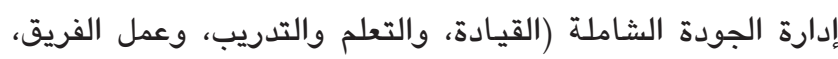

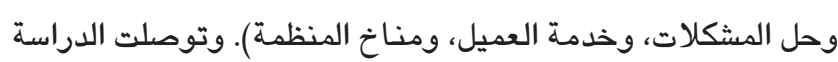

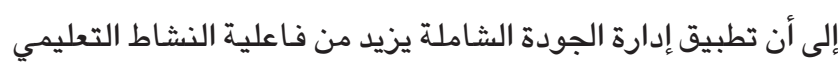

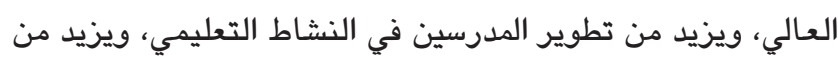
فاعلية التعلم والتعليم. ويتطلب تطبيق إدارة الجودة الشاملة التزام الإدارة العليا وصبرهـا، والعمل كفريق واحد من العاملين جميعهم في كافة المستويات، والتواصل المستمر، والتغيير في ثقافة المنظمة. كما وأجرى (Kysilka and Medinschi, 2009) دراسة في رومانيا هدفت إلى التعرف على أبعاد الجودة ووصف المفاهيم

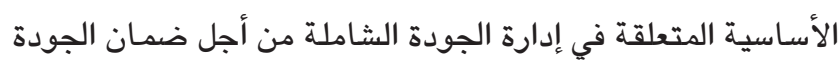

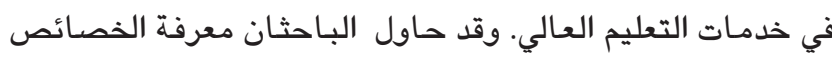

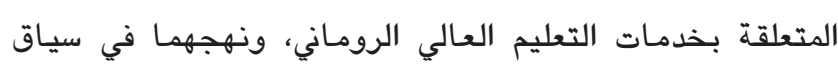
التعليم. وتوصل الباحثان إلى أن الموارد الأساسية في إدارة

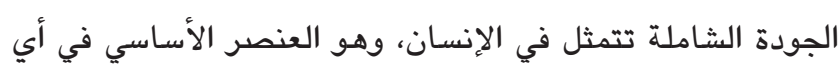

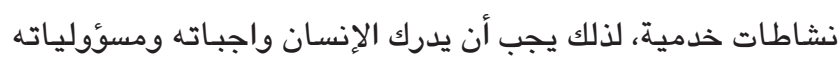

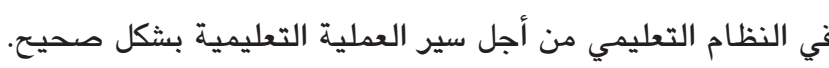
يعتبر تدريب الطلاب مهمة أساسية في النظام التعليمي، ويـالتالي على الآباء أن يكونوا على اطلاع بمستوى تطور أداء أبنائهم في في

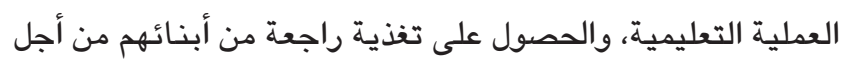

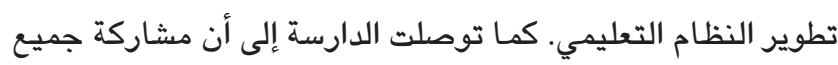
الأطراف في نظام التعليم العالي سيؤدي إلى تحسين مستمر في العمليات التعليمية، ويالتالي الوصول إلى مخرجات مميزة. أجرت أبو الهيجاء (2006) دراسة في الأردن، هدفت إلى قياس مدى تطبيق مبادئ إدارة الجودة الشاملة في كليات التربية الرياضية في الجامعات الحكومية، وإلى ضبط العملية التعليمية وذلك للحصول على مخرجات قادرة على مواكبة التطورات 


\begin{tabular}{|c|c|c|c|}
\hline عدد العينة & حجم العينة & حده (مجتمع الدراسة) & الجامعة \\
\hline 45 & 27 & 241 & الأردنية في العقبة \\
\hline 12 & 5 & 40 & اربد الأهلية \\
\hline 16 & 9 & 80 & عمان الأهلية \\
\hline 62 & 47 & 422 & عمون \\
\hline 15 & 10 & 91 & الزيتونة \\
\hline 31 & 23 & 200 & الثرق الأوسط \\
\hline 15 & 6 & 55 & فيلادلفيا \\
\hline 491 & 341 & 3046 & الدجموع (الحجم) \\
\hline
\end{tabular}

\section{وصف خصائص عينة اللدراسة:}

يتضمن هذا الجزء وصف خصائص أفراد عينة الدراسة وهي الفي (الجنس، الشهادة المنوي الحصول عليها، السنة الدراسية). حيث تم

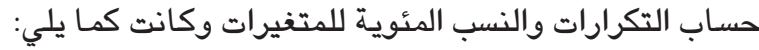

جدول (2)

توزيع أفراد عينة الدراسة من الطلاب تبعاُ للمتغيرات التعريفية

\begin{tabular}{|c|c|c|c|}
\hline النسبة المئوية & التكرار & الفئة & متغيرات الدراسة \\
\hline 69.2 & 340 & الرسمية & نوع الجـامعة \\
\hline 30.8 & 151 & الأهلية & \\
\hline 100.0 & 491 & الكلي & \\
\hline 23.8 & 117 & الهاشمية & الجامعة \\
\hline 9.2 & 45 & اليرموك & \\
\hline 10.0 & 49 & البلقاء التطبيقية - العقبة & \\
\hline 8.8 & 43 & الحسين بن طلال & \\
\hline 8.4 & 41 & الأردنية - عمان & \\
\hline 9.2 & 45 & الأردنية - العقبة & \\
\hline 2.4 & 12 & اربد الأهلية & \\
\hline 3.3 & 16 & عمان الأهلية & \\
\hline 12.6 & 62 & عمون & \\
\hline 3.1 & 15 & الزيتونة & \\
\hline 6.3 & 31 & الثرق الأوسط & \\
\hline 3.1 & 15 & فيلادلفيا & \\
\hline 100.0 & 491 & الكلي & \\
\hline
\end{tabular}

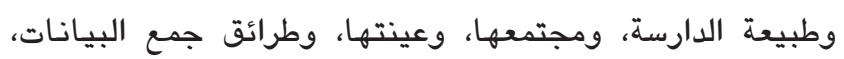

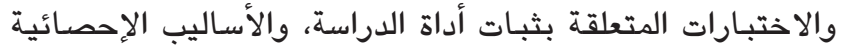
المستخدمة لتحليل البيانات.

نوع وطبيعة اللدراسة:

تعتبر هذه الدراسة ذات طبيعة تطبيقية، وقد تم استخدام

المنهج الوصفي الذي يهدف إلى وصف ظواهر أور أحداث معينة وجمع المعلومات عنها، وتقرير حالتها كما توجد عليه في الواقع.

\section{مجتمع الدراسة: - مجية}

يتكون مجتمع الدراسة من جميع الطلاب وعددهم (3046)

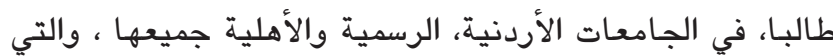
لديها كليات وأقسام سياحة وفنادق، وعددهـا اثنتا عشرة جامعة،

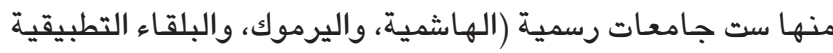
في العقبة، والحسين بن طلال، والأردنية في عمان، والأردنية في العقبة)، وست جامعات أهلية (اريد الأهلية، وعمان الأهلية، وكلية ولانية ولانية

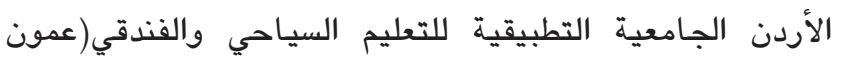
سابقاً)، والزيتونة، والثرق الأوسط، وفيلادلفيا). (وزارة التعليم الإنيا

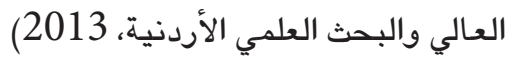

\section{عينة الدراسة:}

طبقاً لعدد مجتمع الدراسة فـإن الحد الأدنى المطلوب لعينة الدارسة هو (341) طالبا (Sekaran and Bougie, 2010: 295). وقد بلغن حجم العينة المختارة من الطلاب (550) طالباً حيث تم استعادة (491) استبانة صالحه للتحليل. وقد تم اختيار العينة

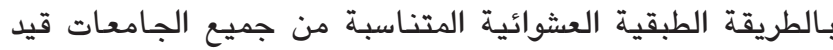

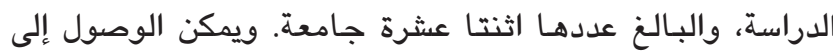

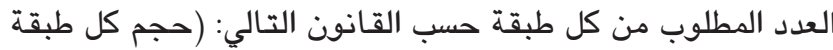
على حده/ حجم مجتمع الدراسة الكلي) * مجموع حجم العينة

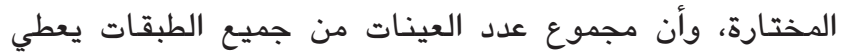

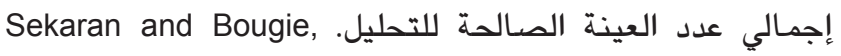
.2010: 292

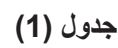

مجتمع وعينة الدراسة لكل من الجامعات الأردنية موضوع الاارسة

\begin{tabular}{|c|c|c|c|}
\hline عدد العينة & حجم العينة & حده (مجتمع الدراسة) & الجامعة \\
\hline 117 & 86 & 765 & الهاشمية \\
\hline 45 & 30 & 272 & اليرموك \\
\hline 49 & 30 & 269 & البقبة الطبيقية في \\
\hline 43 & 29 & 260 & الحسين بن طلال \\
\hline 41 & 39 & 351 & الأردنية في عمان \\
\hline
\end{tabular}


- البُعد الأول: الوعي بمفهوم إدارة الجودة الشاملة، ويقاس

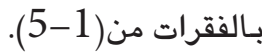

- البُعد الثاني: الاستراتيجية العامة، وتقاس بالفقرات من

- البُعد الثالث: العملية التربوية، وتقاس بالفقرات من

- البُعد الرابح: العملية التعليمية، وتقاس بالفقرات من

(26-17)

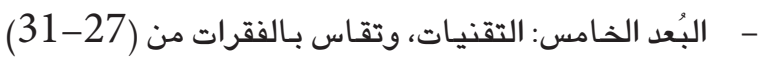

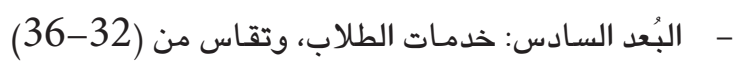

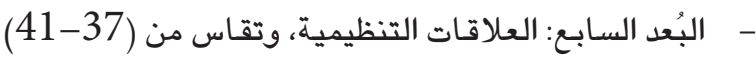
- البُعد الثامن: التغذية الراجعة، وتقاس من (42-46).

جدول (3)

سلم الاستجابة لفقرات الاستبانة

\begin{tabular}{|c|c|c|c|c|}
\hline لا أوافق بشدة & لا أوافق & محايد & موافق & موافق بشدة \\
\hline 1 & 2 & 3 & 4 & 5 \\
\hline
\end{tabular}

من خلال مراجعة الأدبيات السابقة تم تحديد ثلاثة مستويات لقياس مدى تطبيق إدارة الجودة الشاملة في كليات وأقسام القام إدارة تلارة السياحة والفنادق في الجامعات الأردنية، على النحو التالي:

جلول (4)

مستويات تطبيق مفهوم إدارة الجودة الثاملة

\begin{tabular}{|c|c|c|}
\hline درجة التطبيق & النسبـة المئويـة المقابلـة & المستوى \\
\hline ضعيفة & ويقابلها أقل من 50 \% & أقل من 2.5 \\
\hline متوسطة & ويقابلها من 50 \% - إلى 70 \% & من 2.5 إلى 3.5 \\
\hline 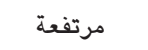 & يقابلها أكثر من 70 \% & أكثر 3.5 \\
\hline
\end{tabular}

ثبات الأداة: تم حساب ثبات أداة الدراسة باستخدام معامل

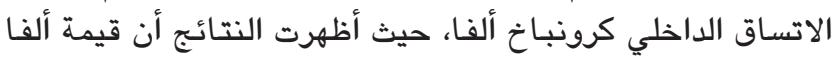

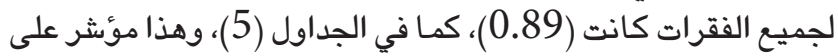

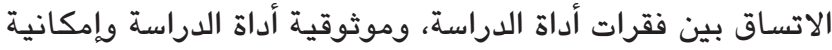
الاعتماد عليها لإجراء التحليل الإحصائي.

\section{جدول (5)}

قيم معامل الاتساق الداخلي لفقرات إدارة الجودة الثاملة

\begin{tabular}{|c|c|}
\hline معامل الثبات & البُعد \\
\hline 0.88 & الوعي بمفهوم إدارة الجودة الشاملة \\
\hline 0.88 & الاستراتيجية العامة \\
\hline 0.88 & العملية التربوية \\
\hline 0.89 & العملية التعليمية \\
\hline 0.88 & التقنيات \\
\hline 0.87 & خدمات الطلاب \\
\hline
\end{tabular}

\begin{tabular}{|c|c|c|c|}
\hline النسبة المئوية & التكرار & الفئة & متغيرات الدراسة \\
\hline 61.1 & 300 & ذكر & الجنس \\
\hline 38.9 & 191 & أنثى & \\
\hline 100.0 & 491 & الكلي & \\
\hline 7.3 & 36 & دبلوم & الشهادة \\
\hline 90.8 & 446 & بكالوريوس & \\
\hline 1.8 & 9 & ماجستير & \\
\hline 100.0 & 491 & الكلي & \\
\hline 25.9 & 127 & الأولى & السنة الدراسية \\
\hline 28.1 & 138 & الثانية & \\
\hline 23.0 & 113 & الثالثة & \\
\hline 21.0 & 103 & الرابعة & \\
\hline 1.8 & 9 & الماجستير & \\
\hline 99.8 & $490 *$ & الكلي & \\
\hline
\end{tabular}

*احد الطلاب لم يقم بتعبئة السؤال المتعلق في السنة الدراسية.

يتبين من الجدول أعلاه توزيع أفراد عينة الدراسة حسب المتغيرات التعريفية وهي كما يلي: ألاه توزي

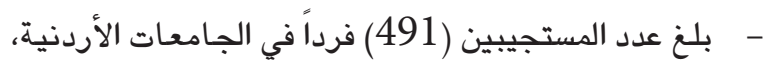
وقد بلغ نسبة المستجيبين (69.2 \% \%) في الجامعات الرسمية، و في الاردية،

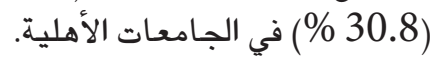

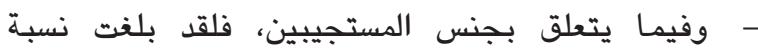

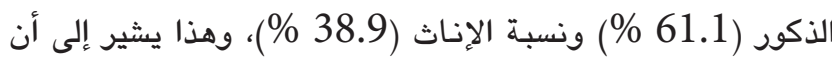

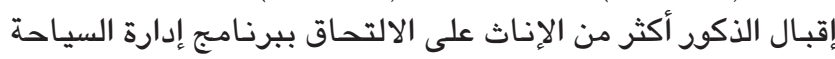

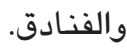

- - أما بالنسبة إلى الشهادة المنوي الحصول عليها، فبلغ

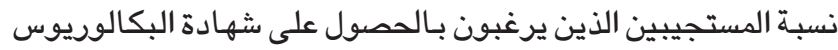
(90.8 \% ) وهي تشكل أعلى نسبة.

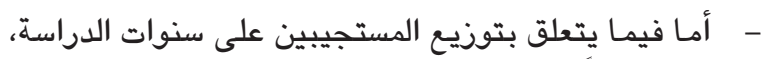
فكانت النسب تقريباً متساوية مـا عدا في مستوى الماجستير.

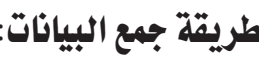

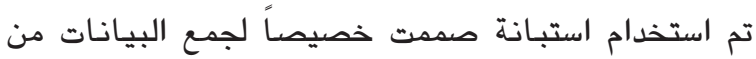

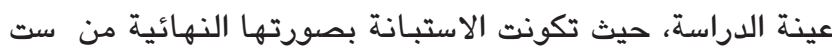

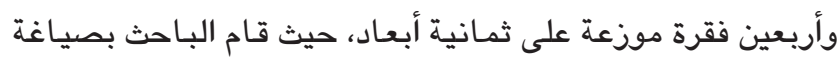

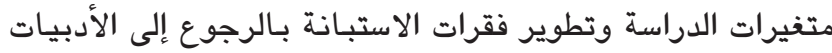

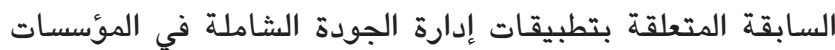
الجامعية ومنها الأطاريح الجامعية التالية: (ابو الهيجاء، الهاءئ 2003 2006)، و (بدح، 2003)، و (دلاشة، 2006) وذلك على النحو التالي: 


\section{تحليل أبعاد الدراسة:}

ما مدى تطبيق إدارة الجودة الشاملة في الجامعات

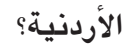

للتعرف على مدى تطبيق إدارة الجودة الشاملة، فقد تم

استخدام المتوسطات الحسابية، والانحرافات المعيارية، والرتبة، إداره،

\begin{tabular}{lr}
\hline التعلاقات التنظيمية \\
\hline 0.87 \\
0.87 \\
0.89 \\
\hline
\end{tabular}

مناقشة النتائج:

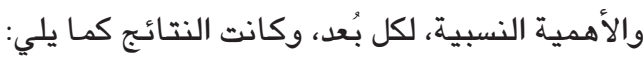

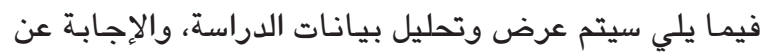

أسئلة الدراسة، واختبار الفرضيات ومناقشتها.

جدول (6)

المتوسطات الحسابية والانحرافات المعيارية والأهمية النسبية لجميع أبعاد الاراسة من وجهة نظر الطلاب

\begin{tabular}{|c|c|c|c|c|c|c|}
\hline درجة التطبيق & الأهمية النسبية & الانحراف المعياري & الوسط الحسابي & الأبعاد & رقم الفقرة & الرتبة \\
\hline 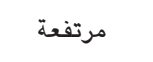 & $\% 78.00$ & 0.70 & 3.90 & الوعي بمفهوم إدارة الجودة الشاملة & 1 & 1 \\
\hline مرتفعة & $\% 77.43$ & 0.72 & 3.87 & الاستراتيجية العامة & 2 & 2 \\
\hline 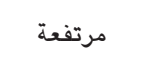 & $\% 75.96$ & 0.83 & 3.80 & 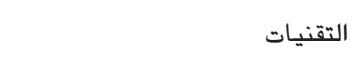 & 5 & 3 \\
\hline مرتفعة & $\% 74.28$ & 0.85 & 3.71 & خدمات الطلاب & 6 & 4 \\
\hline مرتفعة & $\% 74.15$ & 0.88 & 3.71 & العملية التربوية & 3 & 5 \\
\hline مرتفعة & $\% 71.89$ & 0.89 & 3.59 & التغذية الراجعة & 8 & 6 \\
\hline مرتفعة & $\% 71.73$ & 0.91 & 3.59 & العلاقات التنظيمية & 7 & 7 \\
\hline متوسطة & $\% 65.85$ & 0.77 & 3.29 & العملية التعليمية & 4 & 8 \\
\hline مرتفعة & $\% 73.66$ & 0.62 & 3.68 & & & الكلي \\
\hline
\end{tabular}

(العملية التعليمية) حيث بلغت أهميته النسبية أقل من (70 \% \%)،

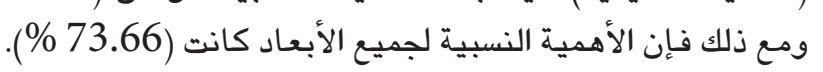

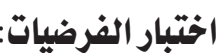

(H1)

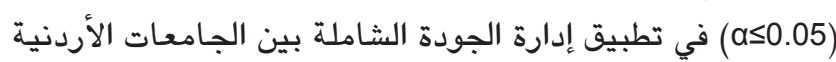

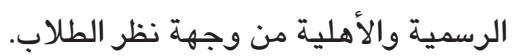

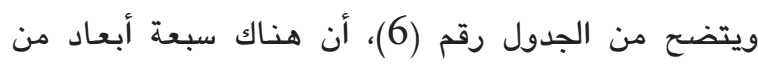

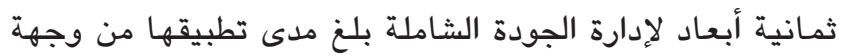

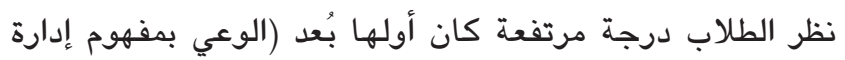

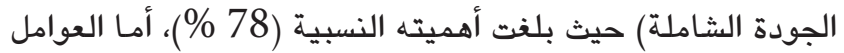
الأخرى التي حصلت على درجة تطبيق مرتفعة فهي كما يلي

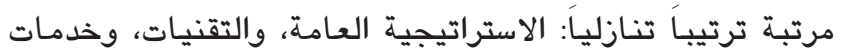
الطلاب، والعملية التربوية، والتفذية الراجعة، والعلاقات التاتية التنظيمية. ويـالمقابل فإنٍ هناك بُعداً حصل على هدى تطبيق متوسط وهو بُعد

جدول (7)

اختبار (t-test) لعينتين مستقلتين لمدى تطبيق إدارة الجودة الثاملة بين الجامعات الأردنية الرسمية والأهلية من وجهة نظر الطلاب

\begin{tabular}{|c|c|c|c|c|c|c|c|}
\hline مستوى الدلالة & قيمة (ت) & الانحر اف المعياري & الوسط الحسابي & درجة الحرية & العدد & نوع الجامعة & الأبعاد \\
\hline \multirow{2}{*}{0.41} & \multirow{2}{*}{-0.83} & 0.70 & 3.88 & \multirow[b]{2}{*}{489} & 340 & رسمية & الوعي بمفهوم إدارة \\
\hline & & 0.69 & 3.94 & & 151 & أهلية & الجودة الثاملة \\
\hline \multirow{2}{*}{0.92} & \multirow{2}{*}{0.10} & 0.72 & 3.87 & \multirow{2}{*}{489} & 340 & رسمية & \multirow{2}{*}{ الاستر اتيجية العامة } \\
\hline & & 0.73 & 3.87 & & 151 & أهلية & \\
\hline \multirow{2}{*}{0.40} & \multirow{2}{*}{0.84} & 0.91 & 3.73 & \multirow{2}{*}{489} & 340 & رسمية & \multirow{2}{*}{ العطلية التربوية } \\
\hline & & 0.82 & 3.66 & & 151 & أهلية & \\
\hline
\end{tabular}




\begin{tabular}{|c|c|c|c|c|c|c|c|}
\hline مستوى الدلالة & قيمة (ت) & الانحر اف المعياري & الوسط الحسابي & درجة الحرية & العدد & نوع الجامعة & الأبعاد \\
\hline \multirow[b]{2}{*}{0.00} & \multirow[b]{2}{*}{-4.14} & 0.68 & 3.19 & \multirow[b]{2}{*}{489} & 340 & رسمية & \multirow[b]{2}{*}{ العملية التعليمية } \\
\hline & & 0.91 & 3.53 & & 151 & أهلية & \\
\hline \multirow[b]{2}{*}{0.20} & \multirow[b]{2}{*}{-1.27} & 0.86 & 3.77 & \multirow[b]{2}{*}{489} & 340 & رسمية & \multirow[b]{2}{*}{ التقنيات } \\
\hline & & 0.77 & 3.87 & & & أهلبة & \\
\hline \multirow[b]{2}{*}{0.02} & \multirow[b]{2}{*}{-2.25} & 0.86 & 3.66 & \multirow[b]{2}{*}{489} & 340 & رسمية & \multirow[b]{2}{*}{ خدمات الطلاب } \\
\hline & & 0.82 & 3.84 & & 151 & & \\
\hline \multirow{2}{*}{0.00} & \multirow{2}{*}{-3.47} & 0.94 & 3.50 & \multirow{2}{*}{489} & 340 & رسمية & \multirow{2}{*}{ لعلاقات التنظيمية } \\
\hline & & 0.82 & 3.79 & & 151 & أهلية & \\
\hline \multirow[b]{2}{*}{0.05} & \multirow[b]{2}{*}{-1.93} & 0.91 & 3.54 & \multirow[b]{2}{*}{489} & 340 & رسمية & \multirow[b]{2}{*}{ التغذية الراجعة } \\
\hline & & 0.86 & 3.71 & & 151 & أهلية & \\
\hline \multirow{2}{*}{0.02} & \multirow{2}{*}{-2.22} & 0.60 & 3.64 & \multirow{2}{*}{489} & 340 & رسمية & \multirow{2}{*}{ الكلي } \\
\hline & & 0.65 & 3.78 & & 151 & أهلية & \\
\hline
\end{tabular}

فروق عند مستوى الدلالة (as0.05) في تطبيق إدارة الجودة الشاملة

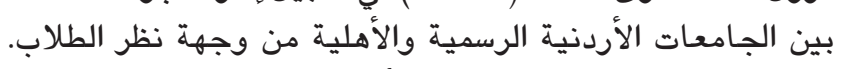

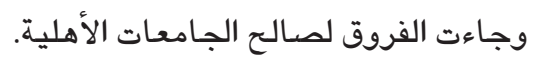

(م2): لا توجد فروق ذات دلالة إحصائية عند مستوى الدلالة

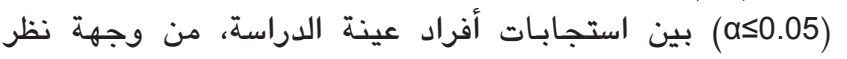

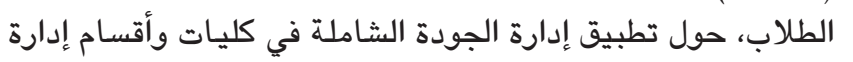

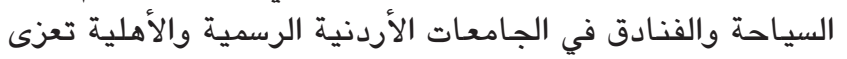
لعامل الجنس.
ويناً على اختبار (t-test) لجميع الأبعاد (الكلي) والمبين

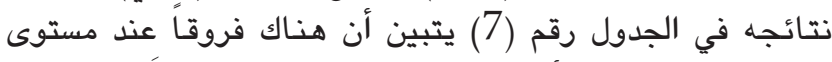

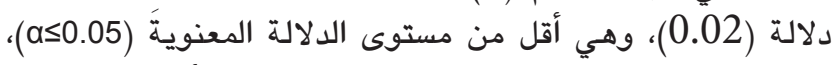

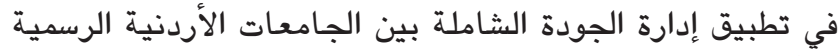

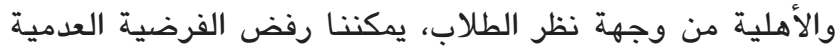

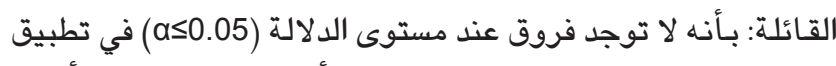

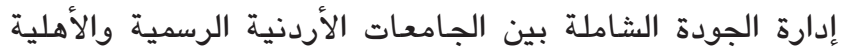

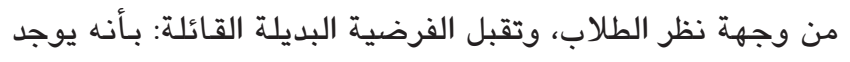

جدول (8)

\begin{tabular}{|c|c|c|c|c|c|c|c|}
\hline مستوى الدلادة & قيمة (ت) & المعياري & الحسابي & الحرية & العدد & الجنس & الأبعاد \\
\hline 0.57 & -0.57 & $\begin{array}{l}0.71 \\
0.70\end{array}$ & $\begin{array}{l}3.89 \\
3.92\end{array}$ & 489 & $\begin{array}{l}300 \\
191\end{array}$ & أنثى & الجودة الشاملة إدمارة \\
\hline 0.04 & -2.06 & $\begin{array}{l}0.76 \\
0.66\end{array}$ & $\begin{array}{l}3.82 \\
3.96\end{array}$ & 489 & $\begin{array}{l}300 \\
191\end{array}$ & ذكر & الاستراتيجية العامة \\
\hline 0.43 & 0.79 & $\begin{array}{l}0.93 \\
0.81\end{array}$ & $\begin{array}{l}3.73 \\
3.67\end{array}$ & 489 & $\begin{array}{l}300 \\
191\end{array}$ & ذكر & العملية التربوية \\
\hline 0.00 & 3.63 & $\begin{array}{l}0.80 \\
0.70\end{array}$ & $\begin{array}{l}3.39 \\
3.14\end{array}$ & 489 & $\begin{array}{l}300 \\
191\end{array}$ & ذكر & العملية التعليمية \\
\hline 0.47 & 0.72 & $\begin{array}{l}0.82 \\
0.84\end{array}$ & $\begin{array}{l}3.82 \\
3.76\end{array}$ & 489 & $\begin{array}{l}300 \\
191\end{array}$ & ذكر & التقنيات \\
\hline 0.90 & 0.13 & $\begin{array}{l}0.89 \\
0.80\end{array}$ & $\begin{array}{l}3.72 \\
3.71\end{array}$ & 489 & $\begin{array}{l}300 \\
191\end{array}$ & ذكر & خدمات الطلاب \\
\hline
\end{tabular}




\begin{tabular}{|c|c|c|c|c|c|c|c|}
\hline الدلالة & قيمة (ت) & المعياري & الحسابي & لدرجة & العدد العد & 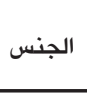 & الأبعاد \\
\hline \multirow{2}{*}{0.18} & \multirow{2}{*}{1.34} & 0.95 & 3.63 & \multirow{2}{*}{489} & 300 & ذكر & \multirow{2}{*}{ العلاقـات التنظيمية } \\
\hline & & 0.86 & 3.52 & & 191 & أنثى & \\
\hline \multirow{2}{*}{0.23} & \multirow{2}{*}{1.20} & 0.92 & 3.63 & \multirow{2}{*}{489} & 300 & ذكر & \multirow{2}{*}{ التغذية الراجعة } \\
\hline & & 0.85 & 3.53 & & 191 & أنثى أنى & \\
\hline \multirow{2}{*}{0.35} & \multirow{2}{*}{0.94} & 0.65 & 3.70 & \multirow{2}{*}{489} & 300 & ذكر & \multirow{2}{*}{ 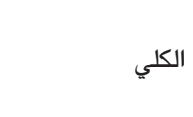 } \\
\hline & & 0.56 & 3.65 & & 191 & أنثى أنى & \\
\hline
\end{tabular}

عند مستوى (as0.05)حول مدى تطبيق إدارة الجودة الشاملة في

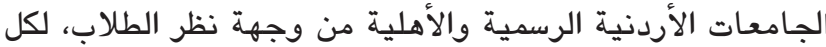

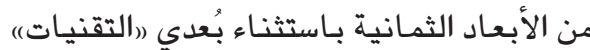
و(خدمات الطلاب) تعزي لمتغير الشهادة المنوي الحصول

لمعرفة اتجاهـات الفروق الزوجية الدالة إحصائياً بين

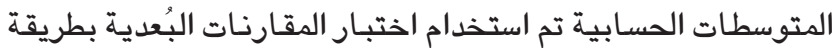

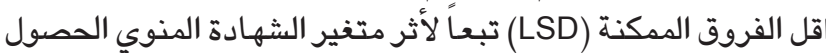

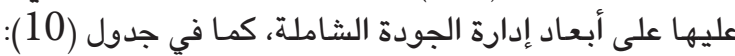

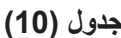

ختبار المقارنات البُعدية بطريقة اقل الفروق المكنة (LSD) تبعاً لأثر متغير الثهادة المنوي

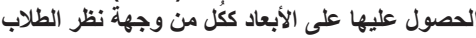

\begin{tabular}{|c|c|c|c|c|}
\hline الدلالة & 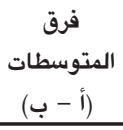 & الشهادة (ب) & الشهادة (أ) & الأبـعاد \\
\hline 0.00 & 0.36 & بكالوريوس & دبلوم & الكلي \\
\hline 0.00 & 0.76 & ماجستير & & \\
\hline 0.00 & -0.36 & دبلوم & بكالوريوس & \\
\hline 0.05 & 0.40 & ماجستير & & \\
\hline 0.00 & -0.76 & دبلوم & ماجستير & \\
\hline 0.05 & -0.40 & بكالوريوس & & \\
\hline
\end{tabular}

ويتضح من الجدول السابق إلى أن الفروق في تطبيق إدارة الجودة الشاملة هي كما يلي: من لئي

- وجود فروق ذات دلالة إحصائية عند مستوى الدلالة

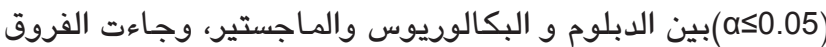

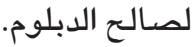

- وجود فروق ذات دلالة إحصائية عند مستوى الدلالة

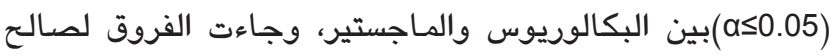

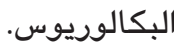

(H4): لا توجد فروق ذات دلالة إحصائية عند مستوى الدلالة

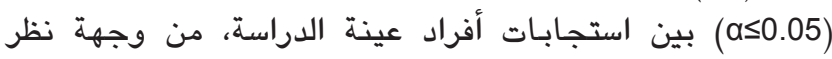

ويظهر من الجدول أعلاه بأنه لا يوجد فروق ذات دلالة

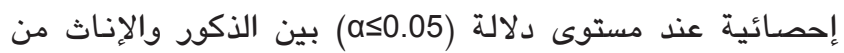

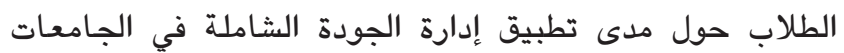

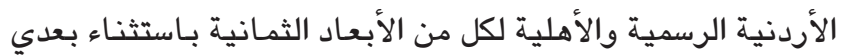

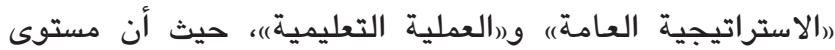

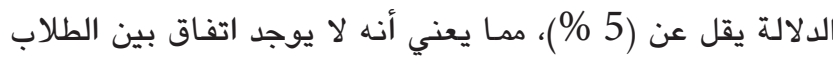

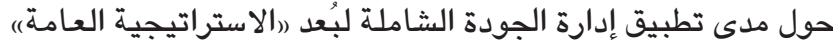

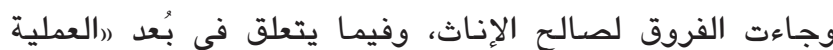
التعليمية)، جاءت الفروق لصالح الذكور.

(H3): لا توجد فروق ذات دلالة إحصائية عند مستوى الدلالة

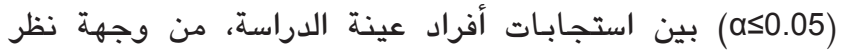
الطلاب، حول تطبيق إدارة الجودة الشاملة في كليات وأقسام إدارة

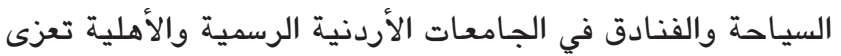
لعامل الشهادة المنوي الحصول ولئاسيها. جذول (9)

تحليل التباين (ANOVA) لددى تطبيق إدارة الجودة الثاملة تبعاً لأثر متغير الثهادة المنوي

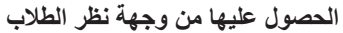

\begin{tabular}{|c|c|c|c|c|c|}
\hline مستوى & قيمة & المربعات & الحرجة & مجموع & الأبعاد \\
\hline 0.00 & 11.74 & 5.53 & 2 & 11.05 & الجودة الشاملة إلدارة \\
\hline 0.04 & 3.25 & 1.68 & 2 & 3.37 & الاستراتيجية العامة \\
\hline 0.00 & 7.36 & 5.61 & 2 & 11.22 & العملية التربوية \\
\hline 0.00 & 20.69 & 11.46 & 2 & 22.92 & العملية التعليمية \\
\hline 0.68 & 0.39 & 0.27 & 2 & 0.53 & التقنيات \\
\hline 0.17 & 1.80 & 1.31 & 2 & 2.61 & خدمات الطلاب \\
\hline 0.01 & 4.51 & 3.70 & 2 & 7.40 & العلاقـات التنظيمية \\
\hline 0.00 & 5.99 & 4.70 & 2 & 9.39 & التغذية الراجعة \\
\hline 0.00 & 8.10 & 3.01 & 2 & 6.02 & الكلي \\
\hline
\end{tabular}

ويظهر من الجدول أعلاه وجود فروق ذات دلالة إحصائية 


\begin{tabular}{|c|c|c|c|c|}
\hline مستوى & $\begin{array}{c}\text { فرق المتوسطات } \\
\text { فأب) }\end{array}$ & 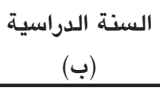 & السنة الدراسية & الأبعاد \\
\hline 0.00 & -0.26 & الأولى & \multirow{4}{*}{ الثالثة } & \\
\hline 0.09 & -0.13 & الثانية & & \\
\hline 0.01 & 0.21 & الرابعة & & \\
\hline 0.08 & 0.37 & الماجستير & & \\
\hline 0.00 & -0.47 & الأولى & \multirow{4}{*}{ الرابعة } & \\
\hline 0.00 & -0.34 & الثانية & & \\
\hline 0.01 & -0.21 & الثالثة & & \\
\hline 0.46 & 0.15 & الماجستير & & \\
\hline 0.00 & -0.62 & الأولى & \multirow{4}{*}{ الماجستير } & \\
\hline 0.02 & -0.50 & الثانية & & \\
\hline 0.08 & -0.37 & الثالثة & & \\
\hline 0.46 & -0.15 & الرابعة & & \\
\hline
\end{tabular}

ويتضح من الجدول السابق إلى أن الفروق في تطبيق إدارة

الجودة الشاملة فيما يتعلق بـالأبعاد ككل هي على النحول النحو التالي: - مجود فروق ذات دلالة إحصائية عند مستوى الدلالة

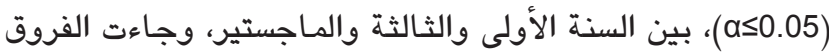

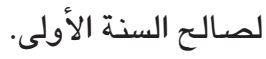

- وجود فروق ذات دلالة إحصائية عند مستوى الدلالة)

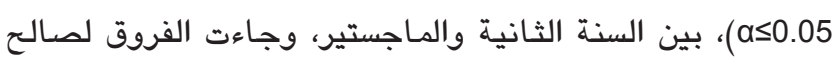

السنة الثانية.

- مجود فروق ذات دلالة إحصائية عند مستوى الدلالة) -

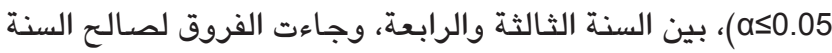

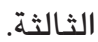

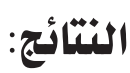

في ضوء تحليل البيانات واختبار الفرضيات فقد توصلت

$$
\text { الدراسة إلى النتائج الآتية: }
$$

ما مدى تطبيق إدارة الجودة الشاملة في كليات وأقسام

إدارة السياحة والفنادق في الجامعات الأردنية الرسمية والأهلية

من وجهة نظر الطلاب؟

بلغخ متوسط درجة التطبيق لإبعاد إدارة الجودة الشاملة

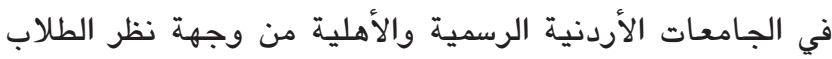
درجة مرتفعة، بـاستثناء بُعد (العملية التعليمية)، الذي حصل على

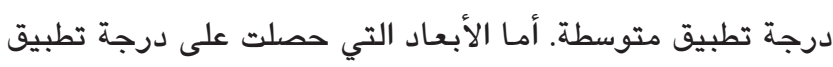
مرتفعة فهي كما يلي مرتبة ترتيباً تنازلياً: (الوعي بمفهوم إدارة
الطلاب، حول تطبيق إدارة الجودة الشاملة في كليات وأقسام إدارة

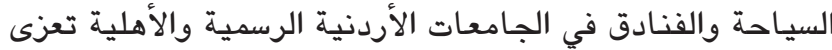
لعامل السنة الدراسية.

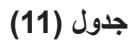

تحليل التباين (ANOVA) لمدى تطبيق إدارة الجودة الثشاملة في الجامعات الأردنية الرسمية والأهلية من وجهة نظر الطلاب تبعاً لمتغير السنة الدراسية

\begin{tabular}{|c|c|c|c|c|c|}
\hline مستوى & قيمة ف & المريعات & الحرية & مجموع & الأبعاد \\
\hline 0.00 & 10.37 & 4.74 & 4 & 18.96 & الجودة الشاملة إدارة \\
\hline 0.00 & 7.93 & 3.92 & 4 & 15.68 & الاستراتيجية العامة \\
\hline 0.00 & 10.23 & 7.44 & 4 & 29.76 & العملية التربوية \\
\hline 0.34 & 1.13 & 0.68 & 4 & 2.70 & العملية التعليمية \\
\hline 0.00 & 7.05 & 4.64 & 4 & 18.56 & التقنيات \\
\hline 0.00 & 7.67 & 5.30 & 4 & 21.18 & خدمات الطلاب \\
\hline 0.00 & 4.76 & 3.83 & 4 & 15.33 & العلاقات التنظيمية \\
\hline 0.00 & 7.18 & 5.45 & 4 & 21.80 & التغذية الراجعة \\
\hline 0.00 & 10.81 & 3.83 & 4 & 15.32 & الكلي - الكي \\
\hline
\end{tabular}

ويظهر من الجدول أعلاه وجود فروق ذات دلالة إحصائية عند

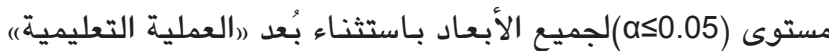

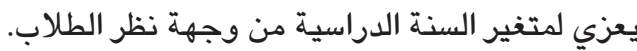
لمعرفة اتجاهـات الفروق الزوجية الدالة إحصـائياً بين

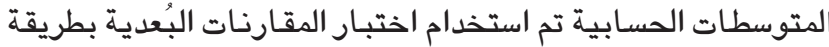

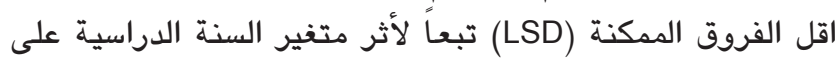

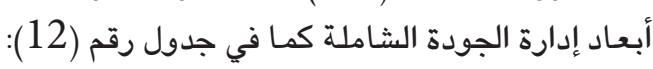

جدول (12)

ختبار المقارنات البُعدية بطريقة اقل الفروق الممكنة (LSD) تبعاً لأثر متغير السنة الدراسية

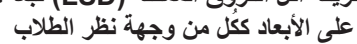

\begin{tabular}{|c|c|c|c|c|}
\hline مستوى & فرق المتوسطات & $\begin{array}{c}\text { السنة الدراسية } \\
\text { (ب) }\end{array}$ & السنة الدراسية & الأبعاد \\
\hline 0.08 & 0.13 & الثانية & \multirow{4}{*}{ الأولى } & الكلي \\
\hline 0.00 & 0.26 & الثالثة & & \\
\hline 0.00 & 0.47 & الرابعة & & \\
\hline 0.00 & 0.62 & الماجستير & & \\
\hline 0.08 & -0.13 & الأولى & \multirow{4}{*}{ الثانية } & \\
\hline 0.09 & 0.13 & الثالثة & & \\
\hline 0.00 & 0.34 & الرابعة & & \\
\hline 0.02 & 0.50 & الماجستير & & \\
\hline
\end{tabular}


العملية التعليمية أكثر من الإناث.

هل هناك فروق في تطبيق إدارة الجودة الشاملة في

الجامعات الأردنية الرسمية والأهلية من وجهة نظر الطلاب تبعاً إلهارة لمتغير الشهادة المنوي الحصول عليها؟ الاردبه

يتبين من الجدول رقم (9) إلى وجود فروق ذات دلالة إحصائية

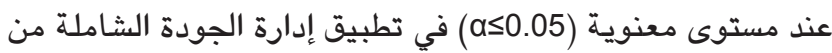
وجهة نظر الطلاب تبعاً لمتغير الشهادة المنوي الحصول عليها وذلك في جميع الأبعاد، بـاستثناء بُعدي (التقنيات) و (خدمات الطيلاتهاب). وتم التوصل إلى أنه يوجد فروق بين الدبلوم والبكالوريوس والماجستير، وجاءت الفروق لصالح الدبلوم، ووجود فروق بين البكالوريوس والماجستير، وجاءت الفروق لصالح البكالوريوس. وقد يعود ذلك إلى عدم اكتمال نضـج الملتحقين أكاديميًا ببرناهج

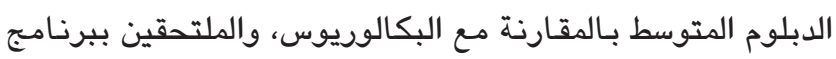

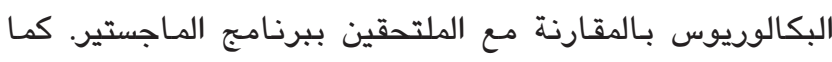

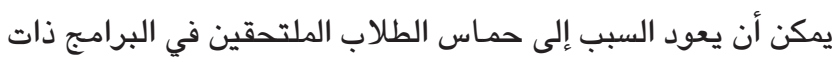

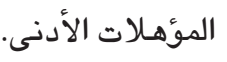

\section{هل هناك فروق في تطبيق إدارة الجودة الشاملة في}

الجامعات الأردنية الرسمية والأهلية من وجهة نظر الطلاب تبعاً

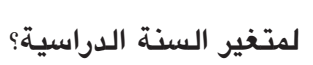

يتبين من الجدول رقم (11) إلى وجود فروق ذات دلالة

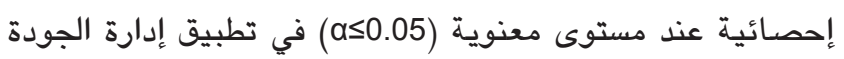

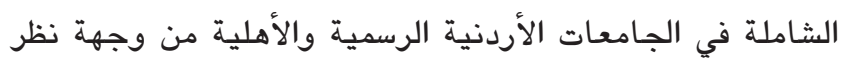
الطلاب تبعاً لمتغير السنة الدراسية في جميع الأبعاد، بـاستثناء

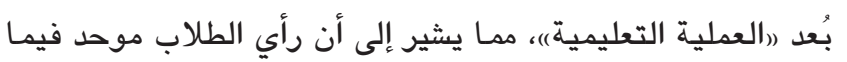

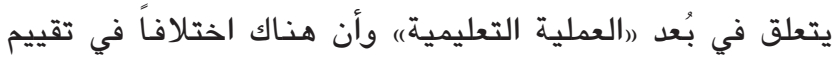
الطلاب لتطبيق إدارة الجودة الشاملة يعزى إلى السنة الدراسية التي ينتمي إليها الطالب. وتم التوصل إلى أنه يوجد فروق بين السنة

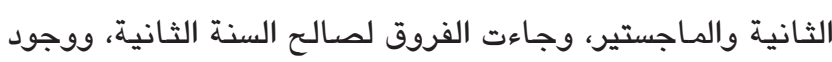
فروق بين السنة الثالثة والأولى، وجاءت الفروق لصالح السنة الأولى، ووجود فروق بين السنة الثالثة والرابعة، وجاءت والثات الفروق الفروق

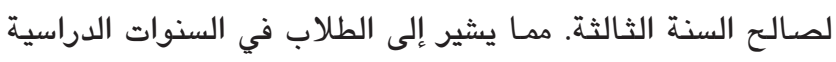

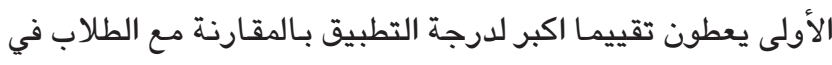

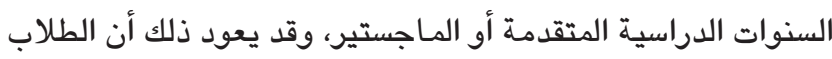

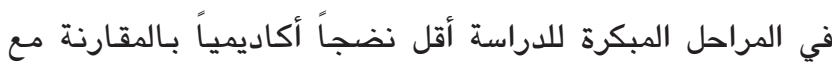

$$
\text { الطلاب في المراحل المتقدمة. }
$$

\section{التوصيات:}

في ضوء النتائج تم صياغة التوصيات الآتية:

1. إيلاء موضوع المواءمة بين مخرجات العمليات التربوية والتعليمية ومتطلبات سوق العمل السياحي والفندقي، وعلى سبيل
الجودة الشاملة)، بـأهمية نسبية بلغت (78.00 \%) و “الاستراتيجية

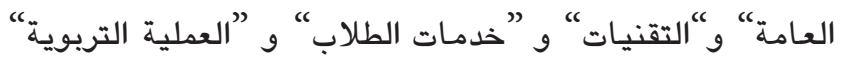
و "التغذية الراجعة“" و "العلاقات التنظيمية“، (انظر الجدول رقم

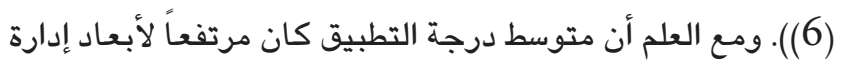

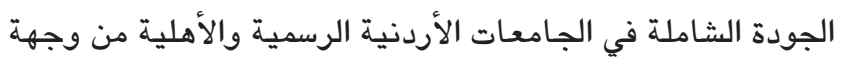

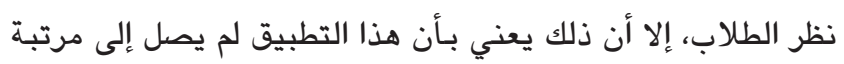

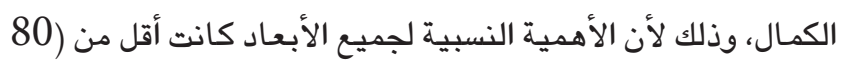

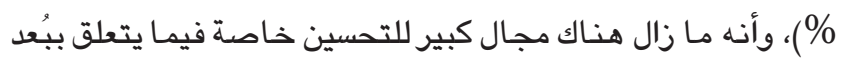

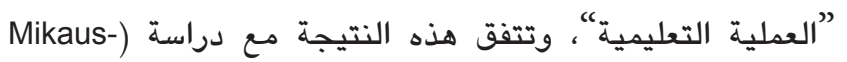

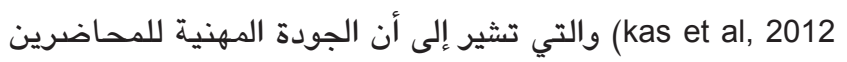
تتعلق في التواصل الفعال مـع الطلاب في المحاضرات، وفي العي العدل الجماعي، وفي ملاءمة المواد المتعلقة في كل تخصص التص على حده، والتطبيق العملي لها. ولهي ماعها.

\section{هل هناك فروق في تطبيق إدارة الجودة الشاملة بين} الجامعات الأردنية الرسمية والأهلية من وجهة نظر الطلاب؟ فرو إلهاب الجودة الثاملة يتبين من الجدول رقم (7)، وجود فروق ذات دلالة إحصائية

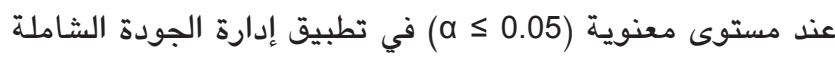

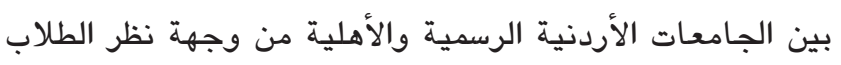

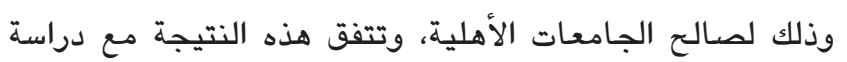

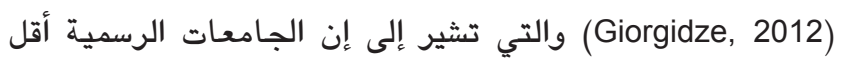

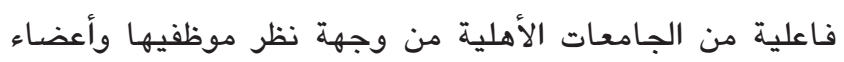
هيئتها التدريسية. ويمكن القول إنّ السبب قد يعود إلى أن الجامعات الأهلية تواجه منافسة شديدة، مما يستدعي أن تقوم بتوفير المزيد

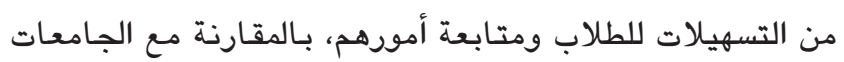

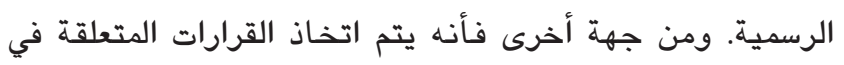

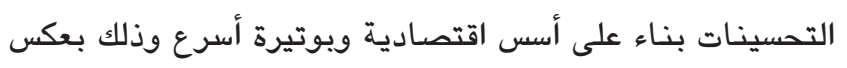
الجـامعات الرسمية والتي تعتمد في العادة على البيروقراطية في وبي اتخاذ القرارات.

\section{هل هناك فروق في تطبيق إدارة الجودة الشاملة في} الجادعات الأردنية الرسمية والأهلية من وجهة نظر الطلاب تبل إلبعاً

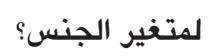

يتبين من الجدول رقم (8) إلى عدم وجود فروق ذات دلالة

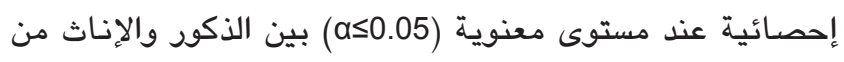
الطلاب في ملى تطبيق إدارة الجودة الشاملة في الجامعات الأردنية

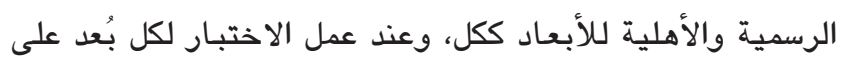

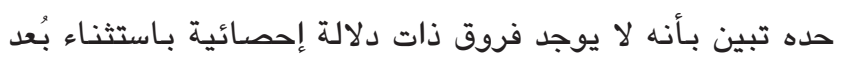

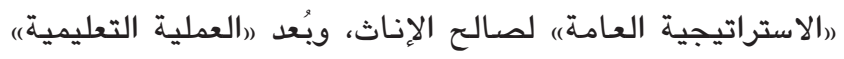

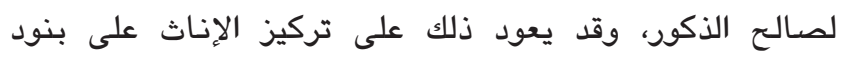

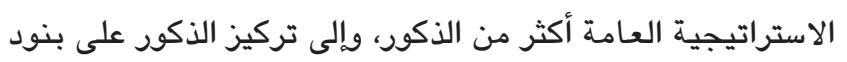


أعضاء الهيئة الإدارية في العمليات التربوية والتعليمية، ومؤسسات قطاع السياحة والفنادق فيما يتعلق بـأداء الخريجين. 9. عمل المزيد من أجل دعوة مؤسسات القطاع السياحي

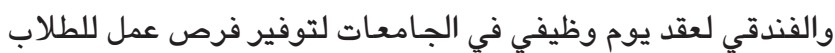
في المستقبل، لأن ذلك يعطي حافزاً قويـاً للطلاب. 10. قيام الجهات الحكومية ومؤسسات القطاع الخاص ببذل المزيد من أجل نثر الثقافة السياحية بين أبناء المجتمع. 11. تشجيع الطلاب على الالتحاق ببرنامج شهادة الدبلوم

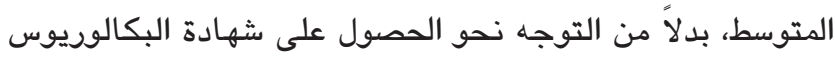

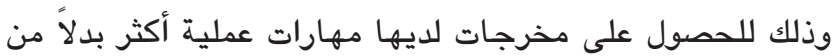
التركيز على الجـانب النظري.

12. المضي قدوماً من الجهات المسؤولة في فصل تخصصي إدارة الفنادق وإدارة السياحة بسبب التوجه العالمي نحو مد التخصصية.

13. استقطاب المزيد من الكفاءات من أعضاء هيئة التدريس في مجال السياحة والفنادق.

\section{المراجع العربية:}

\section{الثران الكريه، سورة التين، سورة الانفطار، سورة الملك.}

1. بدح، أحمد محمد أحمد (2003). إدارة الجودة الشاملة: أنموذج مقترح للتطوير الإداري وإمكانية تطبيقه في الجامعات الأردنية العامة. دكتوراه فلسفة إدارة تربوية، جامعة عمان للدراسات العلي:1-15. جودة، محفوظ أحمد.(2012). إدارة الجودة الشاهلة: مفاهيم وتطبيقات، ط6. عمان، الأردن، دار وائل للنشر. حمود، خضير كاظم. (2007). إدارة الجودة الشاملة، ط3. عمان، الأردن، دار المسيرة للنثر والتوزيع. دلاشة، وليد واصف رشيد. (2006). درجة تطبيق معايير إدارة الجودة

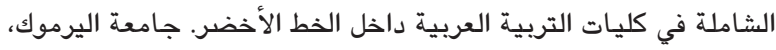
$249-1$

الذيابات، بسام، الذيابات، مراد. (2018). معوقات تطبيق إدارة الجودة

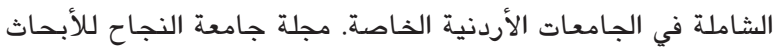

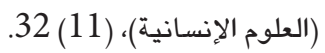
رمان، عرفة حسين عرفة. (2014). أسلوب التخطيط وإدارة الجودة الشاملة، القاهرة، مصر، دار العلم والايمان للنشر والتوزيع. الزواوي، خالد محمد. (2008). الجودة الشاملة في التعليم. القاهرة، مصر،

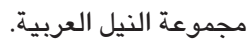
السامرائي، مهدي صالح. (2007).إدارة الجودة الشاملة في القطاعين الإنتاجي والخدمي. بغداد، العراق، دار جرير للنثر والتوزيع. .5
المثال مدى الحاجة إلى فنيين مهرة في المجال.

2. ينصح بأن تعزز إدارات الجامعات موقفها في مجال التخطيط الاستراتيجي وذلك بزيادة حرصها على أن تنسجم خطتها الاستراتيجية مع الخطة الاستراتيجية للتعليم السياحي والفندقي في وزارة التعليم العالي، وإيلاء الاهتمام برأي الطلاب عند إعداد

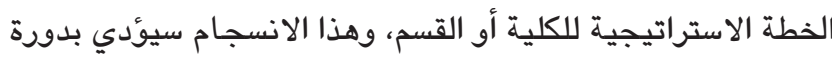
إلى خلق نوع من التوافق في الأهداف، ويـالتالي سيؤدي إلى عمل التحسينات اللازمة عند الحاجة. 3. تعزيز النشاطات اللاصفية وذلك بتنظيم العاب رياضية، وعمل الرحلات السياحية، وتعزيز الثقافة والتربية السياحية والفندقية، وتقديم الخدمات الإرشادية والاجتماعية للطلاب عند الحاجة، وذلك بهدف تمكين الخريجين والذين سيتعاملون مع السياح في المستقبل للتمكن من إعطاء السياح انطباعاً مشرفاً عن الأردن، ويعتبر بمثابة دعاية عن الأردن، مما يشجع السياح على في إعلى تكرار زيـاراتهم في المستقبل وإعطاء انطباع حسن للسياح الآخرين. 4. توفير صالات استقبال، وصالات تدبير منزلي، وخدمات التعلم عبر الانترنت، وملابس التدريب، ومطابخ، وصالات مطاعم، وبرامج حاسوب فندقية وسياحية، وقاعات تدريس مجهزة بالوسائل التعليمية لغايـات تعليم وتدريب الطلاب، لكي تتناسب مع التغير والتطور السريعين في المجال؛ لان التدريب العملي يكسب الطلاب مهارات في مجال السياحة والفنادق، مها يؤهلهم للمباشرة في العمل في قطاع السياحة والفنادق دون حاجة هذه المؤسسات إلى تدريبهم، ويعزز قدراتهم على المنافسة بـالسوق. 5. توفير موقع الكتروني لعرض بحوث الطلاب العلمية، مما يحفز الطلاب على الاستمرار في عمل البحوث خارج النطاق التعليمي مها يزيد من مهاراتهم العلمية.

6. إثراك ممثلي مجالس الطلبة عند اتخاذ قرارات تتعلق بـالطلاب، مها يشعر الطلاب بـأنهم جزء مهم من العمليات التربوية والتعليمية مدا يؤدي إلى تحسين المخرجات التعليمية. 7. عرض الخطط الدراسية قبل اعتمادهـا على مؤسسات قطاع السياحة والفنادق، مما يحقق الاستفادة من خبراتهم الواسعة في مجال السياحة والفنادق، مدا يؤدي إلى الحصول على مخرجات

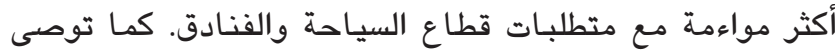
إدارات الجامعات بعمل المزيد من أجل تنظيم لقاءات منتظمة فيما

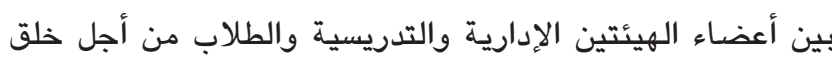
مناخ ودي وغرس روح التعاون بينهم. 8. متابعة رأى الطلاب بعد التحاقهم في سوق العمل ليتسنى للجامعات الأخذ بـآرائهم ومقترحاتهم وعمل التصحيحات اللازمة في العمليات التربوية والتعليمية عند الضرورة، وأن تهتم بآراء 
5. Kysilka, D. and Medinschi, S.(2009). Total Quality Management in Higher Education Services Basic Principles. Asian Journal of Business management , 2, 240-246.

6. McDermott, Robin E., Mikulak, Raymond J. and Beauregard, Michael R. (1993). Employee Driven Quality. New York, U.S.A: Library of Cataloging.

7. Mikalauskas, R., Jasinskas, E. and Svagzdiene, B. (2010). Criteria that Ensure the Quality of Higher Education in Tourism and Sport Management Study Programme. Inzinerine Ekonomika-Engineering Economics, (23)3, 282-290.

8. Ross, Joel E.(1999). Total Quality Management: Text, Cases and Readings, 3 ed. United States of American, St Lucie Press.

9. Sabihaini, Liestyana, Yuli, Astuti and Widhy, Tri.(2010). Experimental Study of Total Quality Management Application in Learning Activity: Indonesia s Case Study. Pak. J, Commer. Soc. Sci, (4) 1, 1-21.

10. Salameh, R. S., Alzydat, M. A. and Alnsour, J. A. (2011). Implementation of (TQM) in the Faculty of Planning and Management at Al-Balqa Applied University. International Journal of Business and Management , (6) 3,194-207.

11. Sekaran, Uma and Bougie Roger. (2010). Research Methods for Business: A Skill Building Approach, 5thed. West Sussex, United Kingdom: John Wiley and Sons, Inc.

12. Soomro, Tariq Rahim and Ahmad, Reyaz. (2012). Quality in Higher Education: United Arab Emirates Perspective. Higher Education Studies,( 2) 4, 148-152.

13. Dale, Barrie and Cooper, Cary .1992. Total Quality and Human Resources. Cornwall, Great Britain: T.J. Press (Padstow) Ltd.

14. Giorgidze, Lali (2012). Exploring Role of Management in Quality Assurance at Private and State Universities of Georgia. Problems of education in the 21st century, Volume 44.

15. Goetsch, David L. and Davis, Stanley B.)2010). Quality Management for Organizational Excellence: Introduction to Total Quality,6th ed. New Jersey: Pearson Prentice Hall.

16. Jablonski, Josep R. (1991). Implementing Total Quality Management: Competing in the 1990, 2 ed. New Mexico, U. S. A: Published by Technical Management Consortium, Inc.

17. Kysilka, D. and Medinschi, S.(2009). Total Quality Management in Higher Education Services Basic Principles. Asian Journal of Business management , 2, 240-246.

18. McDermott, Robin E., Mikulak, Raymond J. and Beauregard, Michael R. (1993). Employee Driven Quality. New York, U.S.A: Library of Cataloging.

19. Mikalauskas, R., Jasinskas, E. and Svagzdiene, B. (2010). Criteria that Ensure the Quality of Higher Education in
9. سليمان، أملني سليمان أحمد. (2019). مدى تطبيق بعض معايير إدارة الجودة الشاملة في كليات جامعة الخرطوم الحكومية وجامعة السودان العالمية الخاصة. مجلة العلوم الاقتصادية والإدارية والقانونية، (2) 3، $.45-21$

10. عساف، عبد المعطي، ومسودة، مازن.(2008).إدارة الجودة والمواصفات.

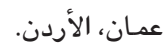

11. عون، وفاء محمد عون، السالم، غادة سالم، الشهراني، نورة زايد. (2018).

تطوير إدارة الجودة الشاملة في نظام التعليم العالي لتحقيق رؤية 2030

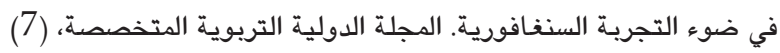
$80-62$ - 4

12. العياشي، زرزار، كريمة، غياد. (2019). إدارة الجودة الشاملة في التعليم:

تأطير مفاهيمي من منظور إسلامي. المجلة العربية للدراسات الإسلامية ذردارية والثرعية، (7)، 215 - 232.

13. مجيد، سوسن شاكر، والزيادات، محمد عواد. (2007). إدارة الجودة

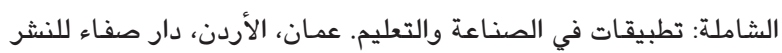
والتوزيع.

14. محسن، عبد الكريم، والنجار، صباح مجيد. (2009). إدارة الإنتاج والعمليات، ط3. عمان، الأردن، دار وائل للنشر.

15. 16. محمد، عبد الرحمن محمد إدريس. (2018). مدى تطبيق مبادئ إدارة

الجودة الشاملة في كليتي الاقتصاد والعلوم الإدارية بجامعة ام درمان العدان

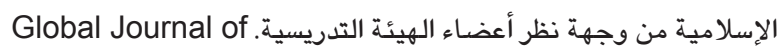

.Economics and Business، (5) 1، 43 - 25 .16

17. المحيسن، زيدون حمد. (2004). الحضارة النبطية. اريد، الأردن، مؤسسة حمادة للدراسات الجامعية والنثر والتوزيع.

18. أبو الهيجاء، شيرين أحمد. (2006) ـ مدى تطبيق إدارة الجودة الشاملة في

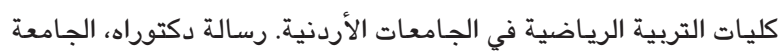

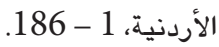

\section{المراجع الأجنبية: - المبية}

1. Dale, Barrie and Cooper, Cary .1992. Total Quality and Human Resources. Cornwall, Great Britain: T.J. Press (Padstow) Ltd.

2. Giorgidze, Lali (2012). Exploring Role of Management in Quality Assurance at Private and State Universities of Georgia. Problems of education in the 21 st century, Volume 44.

3. Goetsch, David L. and Davis, Stanley B.)2010). Quality Management for Organizational Excellence: Introduction to Total Quality,6th ed. New Jersey: Pearson Prentice Hall.

4. Jablonski, Josep R. (1991). Implementing Total Quality Management: Competing in the 1990, 2 ed. New Mexico, U. S. A: Published by Technical Management Consortium, Inc. 
Tourism and Sport Management Study Programme. Inzinerine Ekonomika-Engineering Economics, (23)3, 282-290.

20. Ross, Joel E.(1999). Total Quality Management: Text, Cases and Readings, 3 ed. United States of American, St Lucie Press.

21. Sabihaini, Liestyana, Yuli, Astuti and Widhy, Tri.(2010). Experimental Study of Total Quality Management Application in Learning Activity: Indonesia>s Case Study. Pak. J, Commer. Soc. Sci, (4) 1, 1-21.

22. Salameh, R. S., Alzydat, M. A. and Alnsour, J. A. (2011). Implementation of (TQM) in the Faculty of Planning and Management at Al-Balqa Applied University. International Journal of Business and Management , (6) 3,194-207.

23. Sekaran, Uma and Bougie Roger. (2010). Research Methods for Business: A Skill Building Approach, 5thed. West Sussex, United Kingdom: John Wiley and Sons, Inc.

24. Soomro, Tariq Rahim and Ahmad, Reyaz. (2012). Quality in Higher Education: United Arab Emirates Perspective. Higher Education Studies,( 2) 4, 148-152. 